Article

\title{
Damage by Improvised Incendiary Devices on Carbon Fiber-Reinforced Polymer Matrix Composites
}

\author{
Sebastian Eibl
}

check for updates

Citation: Eibl, S. Damage by Improvised Incendiary Devices on Carbon Fiber-Reinforced Polymer Matrix Composites. J. Compos. Sci. 2021, 5, 72. https://doi.org/ $10.3390 /$ jcs5030072

Academic Editor:

Francesco Tornabene

Received: 22 January 2021

Accepted: 26 February 2021

Published: 5 March 2021

Publisher's Note: MDPI stays neutral with regard to jurisdictional claims in published maps and institutional affiliations.

Copyright: (C) 2021 by the author. Licensee MDPI, Basel, Switzerland. This article is an open access article distributed under the terms and conditions of the Creative Commons Attribution (CC BY) license (https:/ / creativecommons.org/licenses/by/ $4.0 /)$.
Bundeswehr Research Institute for Materials, Fuels and Lubricants, Institutsweg 1, D-85435 Erding, Germany; SebastianEibl@bundeswehr.org

\begin{abstract}
This study focuses on short-term thermal degradation of polymer matrix composites by one-sided impact of improvised incendiary devices (IID). Specimens of two commercial composites $\mathrm{HexPly}{ }^{\circledR}$ 8552/IM7 and M18-1/G939 with various thicknesses (1-8 mm) are systematically investigated as well as sandwich structures thereof, applying various amounts of fire accelerant predominantly in laboratory scale fire tests. Results of preceding large-scale fire tests with IIDs justify the chosen conditions for the laboratory-scale fire tests. The aim is to correlate the amount of fire accelerant with heat damage and residual mechanical strength. Thermal damage is characterized visually and by ultrasonic testing, infrared spectroscopy, and residual interlaminar shear strength. Matrix degradation and combustion only contribute to the overall amount of released heat by the fire accelerant for thin and especially vertically aligned panels as tested by a cone calorimeter (without electrical heating), but not for horizontally orientated and thicker panels. Degradation processes are discussed in detail. Protective effects are observed for typical coatings, a copper mesh applied for protection against lightning strike, combinations thereof as well as an intumescent coating. Especially sandwich structures are prone to severe damage by assaults with IID, such as Molotov cocktails.
\end{abstract}

Keywords: carbon fiber reinforced polymer; improvised incendiary device; fire accelerant

\section{Introduction}

Improvised incendiary devices (IID) have been used for a long time especially by terrorists, as they are cheap and easy to prepare [1-4]. They represent a severe danger in particular for materials with a low thermal stability or combustible materials such as polymers. Carbon fiber-reinforced polymers (CFRP) are widely used in defense industry for vehicles and aircraft threatened by this type of assault. However, there is not sufficient knowledge about the effect of these fire accelerants on CFRP, as these data are often classified and not published. Many investigations on thermal damage of CFRP typically focus on accidentally overheating due to pipe bursts, malfunctions in electric equipment, during repair, engine overheating or impingement of engine exhaust, lightning strikes or fires etc., [5]. Knowledge about the relation between input of thermal energy, degradation of the polymer matrix, and the loss of mechanical strength of composite materials is of wide interest, especially in aircraft industry. Thermal degradation of composites is typically associated with softening and decomposition of the matrix material as well as the development of cracks accompanied by the degradation of the interphase between fiber and matrix. Matrix cracking and delamination have been shown to occur after thermal exposure by many authors [6-11]. Rapid heating beyond the temperature necessary for a degradation of the polymer matrix (typically approx. 300 to $400{ }^{\circ} \mathrm{C}$ ) up to ignition temperature is achieved for example by irradiation experiments. Heat fluxes of $35 \mathrm{~kW} / \mathrm{m}^{2}$ are characteristic for developing, and $50 \mathrm{~kW} / \mathrm{m}^{2}$ for fully developed fires [6].

Thermal degradation effects are typically described by residual strength and by nondestructive testing methods such as ultrasonic testing and infrared spectroscopy [12]. Infrared spectroscopy (IR) is widely used to pursue polymer matrix decomposition $[13,14]$, 
especially in a range of incipient heat damage, where visual and ultrasonic inspection is not sensitive enough. In previous studies [15-17] an empirical correlation was established between the degradation of the polymer matrix traced by infrared spectroscopy and the residual mechanical strength for the investigated CFRP HexPly ${ }^{\circledR}$ 8552/IM7 and M181/G939. Also chemometric techniques were proposed to separately determine temperature and duration of a thermal pre-load [18].

This study focuses on short-term thermal degradation of CFRP by the influence of liquid fire accelerants. One-sided impact of typical improvised fuel mixtures is predominantly investigated in laboratory-scale fire tests. The amount of fire accelerant is chosen to be comparable to a realistic scenario when the ratio of liquid to CFRP surface is considered [19]. Therefore, large-scale fire tests with IIDs are carried out to justify the chosen conditions for the laboratory-scale fire tests.

Under these conditions no thermal equilibrium throughout the composite is reached, but high temperature gradients occur. Temperature at the samples' surface is in the range of the ignition temperature of the resin matrix. A systematic variation of the amount of fire accelerant, material thickness, monolithic, and sandwich structures as well as horizontal and vertical alignment of samples is carried out, in order to investigate the influence of these basic parameters on the damage of the CFRP. Two CFRP materials common in defense and aviation industry (HexPly ${ }^{\circledR}$ 8552/IM7 and M18-1/G939) are investigated. Reaction-to-fire properties of these materials have already been characterized for a forced combustion by cone calorimetry $[20,21]$.

Additionally, the influence of a typical coating, an integrated copper mesh usually applied for the protection against lightning strike, and combinations thereof are considered, as well as the protection potential by an intumescent coating. With respect to the intumescent coating, differences of protection efficiency is compared for heat impact by irradiation and improvised fire accelerants.

It is the goal of this work to assess how CFRP structures used in defense industry are prone to failure due to assaults by improvised incendiary devices. A deep insight into degradation mechanisms is gained. The aim is to correlate the amount of applied thermal energy with heat damage, to assess detectability of the damage and to predict residual mechanical strength.

\section{Material}

All tests are performed with carbon fiber-reinforced epoxy systems HexPly ${ }^{\circledR}$ 8552/IM7 (unidirectional prepreg) and HexPly ${ }^{\circledR}$ M18-1/G939 (fabric prepreg) from Hexcel Composites $\mathrm{GmbH}$, Stade, Germany (subsequently assigned as 8552/IM7 and M18-1/G939). Both matrix systems of the CFRP "8552" and "M18-1" consist of aromatic epoxy resins (29 wt $\%$ and $36 \mathrm{wt} \%$ ), which are toughened with the temperature-resistant thermoplastics polyethersulfone (6 wt\% in "8552") and polyetherimide (6 wt\% in "M18-1"), respectively [22,23]. The "M18-1" matrix additionally contains zinc borate (1.6 wt\%) and magnesium hydroxide (1.6 $\mathrm{wt} \%)$ as flame retardants [21].

The prepared 8552/IM7 and M18-1/G939 laminates consist of 1, 2, 4, 6, and $8 \mathrm{~mm}$ thick quasi-isotropic lay-ups:

8552/IM7: $\quad[(45 / 90 / 135 / 0)]_{S} ;\left[(45 / 90 / 135 / 0)_{2}\right]_{S} ;\left[(45 / 90 / 135 / 0)_{4}\right]_{S} ;\left[(45 / 90 / 135 / 0)_{6}\right]_{S}$; $\left[(45 / 90 / 135 / 0)_{8}\right]_{S} ;$ and

M18-1/G939: $[(+45 /-45)(90 / 0)(-45 /+45)(0 / 90)]_{S} ;[(+45 /-45)(90 / 0)(-45 /+45)(0 / 90)]_{2 S}$; $[(+45 /-45)(90 / 0)(-45 /+45)(0 / 90)]_{3 s}$, etc.

They are cured in an autoclave according to the manufacturer's recommended conditions [22]. Ultrasonic C-scans are performed to ensure that the test laminates are free of delaminations and voids. The laminates are cut into $100 \mathrm{~mm} \times 100 \mathrm{~mm}$ panels for laboratory experiments in a cone calorimeter (without electrical heating) using a watercooled diamond wheel saw and dried at $70{ }^{\circ} \mathrm{C}$. Large-scale experiments are performed with $330 \mathrm{~mm} \times 330 \mathrm{~mm}$ M18-1/G939 panels (see Figure 1). An overview of all prepared samples and experimental conditions is given in Tables 1 and 2. 

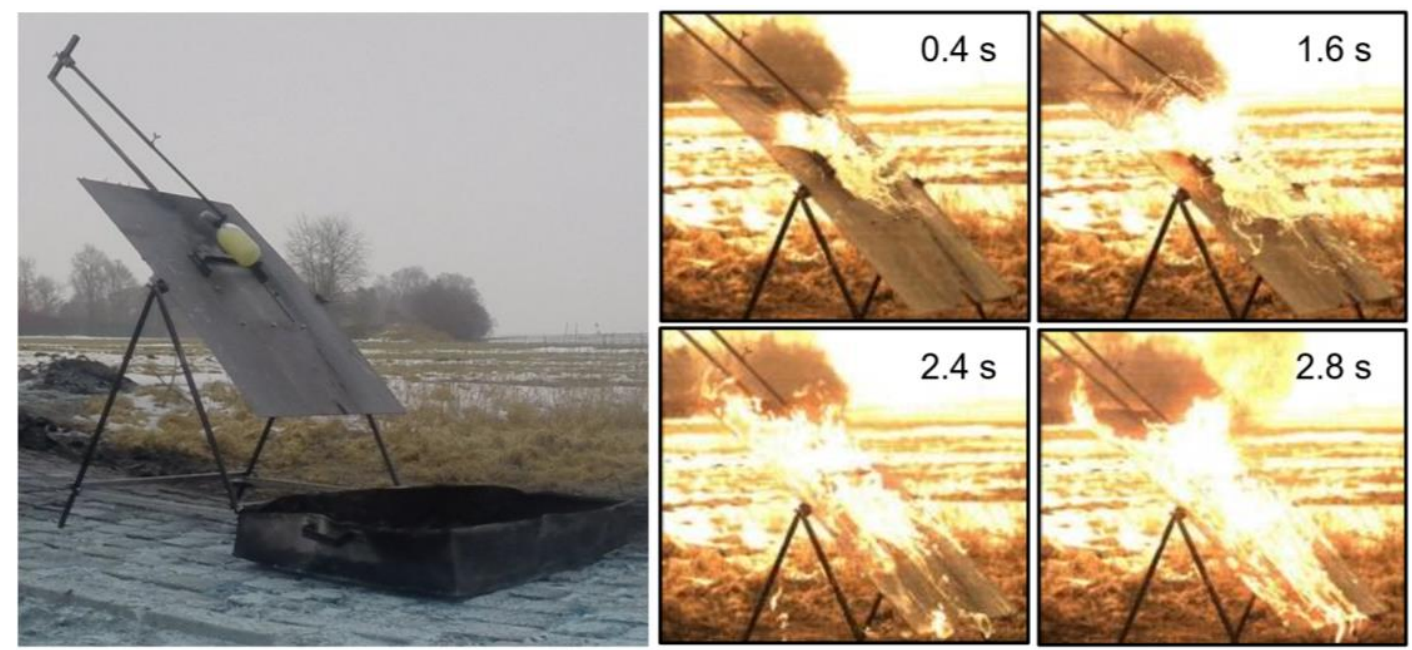

Figure 1. Steel sample holder with a $45^{\circ}$ installed $330 \mathrm{~mm} \times 330 \mathrm{~mm}$ carbon fiber-reinforced polymers (CFRP) panel used for the fire tests, and images of a high-speed camera representing the application of an improvised incendiary devices (IID).

As improvised incendiary device (IID) a fire accelerant mixture of petrol (10 vol.\%) readily igniting and diesel fuel (90 vol.\%) for sustained combustion is chosen for the laboratory experiments in the cone calorimeter. Viscous and sticky mixtures are obtained, when polystyrene foam and toluene are added (mass ratio: 3:1:4:2 for diesel fuel:petrol:toluene:polystyrene foam), as used for the preceding more realistic IID fire tests (see Figure 1). However, thin films of polystyrene residues on the samples after the combustion experiments lead to less reproducible results. Therefore, all laboratory experiments are conducted without thickener, even though thickeners are typical for Molotov cocktails. By preceding large-scale experiments with $330 \mathrm{~mm} \times 330 \mathrm{~mm}$ large M18-1/G939 samples (see Figure 1), it is proven that the amount of fire accelerant related to the surface area of a CFRP $\left(\sim 1000-\sim 3000 \mathrm{~g} / \mathrm{m}^{2}\right)$ and the duration of impact are comparable for laboratory experiments and real assaults [19]. Samples used for the large-scale fire tests are summarized in Table 1. Additionally, larger amounts $\left(>30 \mathrm{~g} / 0.01 \mathrm{~m}^{2}\right)$ are applied for thick samples in laboratory experiments (see Table 1).

A two-component polyesterurethane is used as the top coat based on aliphatic diand tri-isocyanates "Decklack 472-22, 754H + Hardener 400" [24] with grey color typical for military aircraft: "FS 35237" (Federal Standard 595C, Paint Spec) with semi-gloss (reflectometer values: $20 \pm 5$ at $60^{\circ}$, EN ISO 2813 [25]). It is provided by Mankiewicz $\mathrm{GmbH}$ (Hamburg, Germany). The resulting coating is $50 \pm 3 \mu \mathrm{m}$ thick, and its properties are specified in [26].

Table 1. Summary of all investigated samples and experimental conditions of realistic, large-scale IID fire tests with $330 \mathrm{~mm}$ $\times 330 \mathrm{~mm}$ M18-1/G939 panels. Selected test results are additionally given.

\begin{tabular}{|c|c|c|c|c|c|c|c|c|}
\hline \multirow{2}{*}{$\begin{array}{l}\text { Thick-ness } \\
{[\mathrm{mm}]}\end{array}$} & \multirow{2}{*}{$\begin{array}{c}\text { Vol. Fire } \\
\text { Accelerant [L] }\end{array}$} & \multirow{2}{*}{$\begin{array}{l}\text { Flame } \\
\text { Time [s] }\end{array}$} & \multirow{2}{*}{$\begin{array}{c}\text { Tilt Angle } \\
{\left[{ }^{\circ}\right]}\end{array}$} & \multirow{2}{*}{$\begin{array}{l}\text { Mass Loss } \\
{[\%]}\end{array}$} & \multicolumn{2}{|c|}{$\begin{array}{c}\text { Max. Temperature }\left[{ }^{\circ} \mathrm{C}\right] \\
\text { At Side }\end{array}$} & \multirow{2}{*}{$\begin{array}{c}\text { Norm. } \\
\text { Resid. } \\
\text { ILSS [\%] }\end{array}$} & \multirow{2}{*}{$\mathbf{I R} * *[-$} \\
\hline & & & & & Front & Back & & \\
\hline 2 & 0.5 & 222 & $45^{\circ}$ & 0 & $\sim 690$ & 213 & 100 & 94 \\
\hline 2 & 0.5 & 308 & hori-zontal & $\sim 11$ & $\sim 800$ & 335 & $\sim 18$ * & $\sim 21$ \\
\hline 4 & 1 & 585 & hori-zontal & 0 & $\sim 610$ & 296 & - & - \\
\hline 4 & 1 & 265 & hori-zontal & 0 & $\sim 590$ & 235 & - & - \\
\hline 6 & 1 & 400 & hori-zontal & $\sim 3$ & $\sim 900$ & 234 & - & - \\
\hline
\end{tabular}

* Samples taken from the center of the panel fail in various plies. Value therefore does not represent realistic interlaminar shear strength

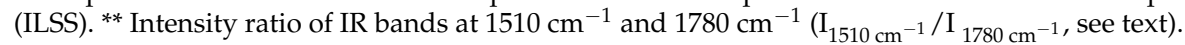


Table 2. Summary of all investigated samples and experimental conditions for laboratory tests. For each condition, the minimum residual interlaminar shear strength is given (ILSS is related to the initial values: $71 \mathrm{~N} / \mathrm{mm}^{2}$ for $8552 / \mathrm{IM} 7 \mathrm{and}$ $65 \mathrm{~N} / \mathrm{mm}^{2}$ for M18-1/G939; standard deviation is $\sim 10 \%$ of the given value).

\begin{tabular}{|c|c|c|c|c|c|c|c|c|c|c|c|}
\hline \multirow{2}{*}{$\begin{array}{c}\text { CFRP } \\
\text { Material }\end{array}$} & \multirow{2}{*}{$\begin{array}{c}\text { Thickness } \\
\text { [mm] }\end{array}$} & \multirow{2}{*}{ Remark } & \multicolumn{9}{|c|}{ ILSS in \%For Mass Fire Accelerant [g] } \\
\hline & & & 5 & 10 & 15 & 20 & 25 & 30 & 40 & 50 & 75 \\
\hline \multirow{18}{*}{$8552 / \mathrm{IM} 7$} & 1 & - & 32 & 0 & 0 & 0 & - & 0 & 0 & - & - \\
\hline & 2 & - & 68 & 44 & 7 & 0 & 0 & - & - & - & - \\
\hline & 2 & vertically aligned & 82 & 45 & 0 & 0 & - & 0 & 0 & - & - \\
\hline & 2 & coated & 75 & 54 & 42 & 28 & 25 & - & - & - & - \\
\hline & 2 & copper mesh & - & 62 & - & 25 & - & 11 & 8 & - & - \\
\hline & 2 & copper m. + coat & - & 59 & - & 14 & - & 11 & 7 & - & - \\
\hline & 2 & $\begin{array}{l}\text { intumesc. } \\
\text { coating }\end{array}$ & - & 72 & - & 65 & - & 61 & 25 & - & - \\
\hline & 4 & - & - & 72 & - & 59 & 45 & 0 & 0 & - & - \\
\hline & 4 & coated & - & 92 & - & 80 & - & 54 & 56 & - & - \\
\hline & 4 & copper mesh & - & 96 & - & 85 & - & 73 & 42 & - & - \\
\hline & 4 & copper m. + coat & - & 61 & - & 42 & - & 35 & 20 & - & - \\
\hline & 4 & $\begin{array}{l}\text { intumesc. } \\
\text { coating }\end{array}$ & - & 83 & - & 76 & - & 70 & 68 & - & - \\
\hline & 6 & - & - & - & 86 & - & 92 & 82 & - & - & - \\
\hline & 6 & coated & - & - & - & 92 & - & 82 & 46 & 28 & - \\
\hline & 6 & copper mesh & - & 101 & - & 96 & - & 82 & 86 & - & - \\
\hline & 6 & copper m.+ coat & - & 54 & - & 41 & - & 41 & 37 & - & - \\
\hline & 6 & $\begin{array}{l}\text { intumesc. } \\
\text { coating }\end{array}$ & - & 90 & - & 79 & - & 70 & 77 & - & - \\
\hline & 8 & - & - & 77 & 87 & 83 & - & 79 & 76 & 77 & 68 \\
\hline \multirow{8}{*}{$\begin{array}{c}\text { M18-1/ } \\
\text { G939 }\end{array}$} & 1 & - & 57 & 0 & 0 & 0 & - & 0 & 0 & - & - \\
\hline & 2 & - & 54 & 31 & 0 & 0 & - & 0 & & - & - \\
\hline & 2 & vertically aligned & 83 & 0 & 0 & 0 & - & 0 & 0 & 0 & - \\
\hline & 2 & coated & 80 & 37 & 28 & 23 & - & 22 & - & - & - \\
\hline & 4 & - & - & 71 & 54 & 23 & 22 & - & 8 & - & - \\
\hline & 6 & - & - & - & 85 & 82 & 83 & 85 & 71 & 77 & - \\
\hline & 8 & - & - & 91 & 83 & 82 & - & 72 & 72 & 63 & 0 \\
\hline & 16.5 & sandwich & - & $6^{*}$ & $3 *$ & $2 *$ & - & - & - & - & - \\
\hline
\end{tabular}

${ }^{*}$ related to initial force at break $(825 \mathrm{~N})$ in a four point bending test; - no test performed; $0 \%$ indicate samples, for which plies already fall apart before ILSS testing.

A water-dilutable two component intumescent coating is used ( $2 \mathrm{~K}$ - Brandschutzlacksystem K1 + K2 by AISCO Chemieprodukte GmbH, Freiburg, Germany) with a proprietary but typical composition consisting predominantly of (poly) phosphoric acid $(\mathrm{K} 1,16 \% \mathrm{P})$ and melamine $(\mathrm{K} 2,26 \% \mathrm{~N})$. About $2 \mathrm{~g}$ (dry mass) coating is squeegeed on each $100 \mathrm{~mm} \times 100 \mathrm{~mm}$ cured test panel resulting in a film thickness of $300 \mu \mathrm{m}$ which typically forms an expanded foam of $4 \mathrm{~cm}$ in irradiation experiments [27].

For some samples a copper mesh $\left(\sim 120 \mathrm{~g} / \mathrm{m}^{2} ; \sim 0.05 \mathrm{~mm}\right.$ wire diameter $)$ is additionally applied at the surface of $8552 /$ IM7 samples before curing.

Selected $4 \mathrm{~mm}$ thick 8552/IM7 specimens are equipped with eight thermocouples (type K) prior to curing under the 1st $(\sim 0.125 \mathrm{~mm}), 8$ th $(\sim 1 \mathrm{~mm}), 12$ th $(1.5 \mathrm{~mm}), 16$ th $(\sim 2 \mathrm{~mm}), 21 \mathrm{st}(\sim 2.6 \mathrm{~mm}), 26 \mathrm{th},(\sim 3.25 \mathrm{~mm})$, and 31st $(\sim 3.9 \mathrm{~mm})$ ply, in order to trace the temperature rise in the bulk material during combustion; for M18-1/G939 underneath the 3rd $(\sim 0.75 \mathrm{~mm}), 5$ th $(\sim 1.25 \mathrm{~mm}), 7$ th $(1.75 \mathrm{~mm}), 9$ th $(\sim 2.25 \mathrm{~mm}), 11$ th $(\sim 2.75 \mathrm{~mm}), 13$ th, $(\sim 3.25 \mathrm{~mm})$, and 15th $(\sim 3.75 \mathrm{~mm})$ ply. The thermocouples are located close to the center of the panels.

Sandwich specimens are prepared by two $1 \mathrm{~mm}$ thick quasi-isotropic M18-1/G939 laminates bonded to a $14.7 \mathrm{~mm}$ thick nomex ${ }^{\circledR}$ honeycomb core resulting in $16.5 \mathrm{~mm}$ thick panels. The components are pressed $\left(1000 \mathrm{~N} / \mathrm{m}^{2}, 12 \mathrm{~h}\right)$ prior to curing. 


\section{Experimental}

For realistic IID experiments, $330 \mathrm{~mm} \times 330 \mathrm{~mm}$ M18-1/G939 panels are placed in the center of an inclinable $120 \mathrm{~cm} \times 90 \mathrm{~cm}$ steel panel as part of a specially designed test apparatus (see Figure 1). To a glass bottle, containing at maximum 1 liter of the liquid IID, a burning textile wick is attached. The bottle is guided along its way to be shattered above the CFRP panel in order to provide reproducible test conditions. The tests are filmed with a high-speed camera Optronis CamRecord CR1000 at 1000 frames per second. Test conditions are summarized in Table 1.

For laboratory scale experiments, $100 \mathrm{~mm} \times 100 \mathrm{~mm}$ samples are put in a specially designed, quadratic steel holder (inner frame: $98 \mathrm{~mm} \times 98 \mathrm{~mm}$ ) allowing a horizontal alignment of the panels and the application of the liquid fire accelerant (Figure 2).
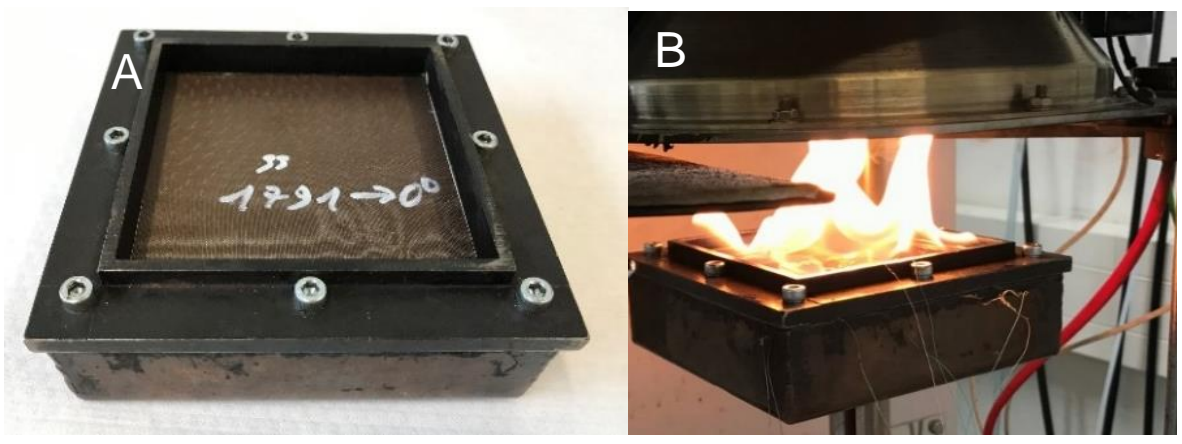

Figure 2. Sample holder with a horizontally installed CFRP panel (A) used for the fire tests in a cone calorimeter (B). (For reference measurements of the fire accelerant, the CFRP panel is substituted by a steel plate. Vertically aligned CFRP panels are positioned at the right edge of the frame with a horizontal steel plate in the sample holder).

The CFRP panel and the frame screws are fixed tight with a tape sealing in between to prevent the leaking of liquids. For reference experiments a steel plate is used. After ignition of the liquid fire accelerant with a lighter, the combustion is investigated by a cone calorimeter (Fire Testing Technology UK, according to ISO 5660 [28]). No external irradiation by the cone heater is applied. Temperatures are recorded by type-K thermocouples fixed on the centers of the front side and at three positions on the backside of the panels with a temperature-resistant tape (see Figure 3). Vertically aligned composite samples are put at one edge of the sample holder, which is filled with the fire accelerant on a horizontal steel plate. All fire tests are repeated once for each condition and results are averaged.

The thermally degraded samples are weighed and cut into test specimens for interlaminar shear strength (ILSS) testing. Size and position of the specimens are shown in Figure 3. ILSS-testing is chosen because small specimens allow to trace the inhomogeneous damage throughout the panel. ILSS-tests for the specimen with a thickness of $2 \mathrm{~mm}$ are performed in accordance to DIN EN 2563 [29]. For the specimen with a nominal thickness of $4 \mathrm{~mm}$, the distance of the supports is set to $20 \mathrm{~mm}$ and for the specimen with a nominal thickness of $6 \mathrm{~mm}$ to $30 \mathrm{~mm}$. The radii of loading nose and supports for the specimen with a nominal thickness of $4 \mathrm{~mm}$ and $6 \mathrm{~mm}$ are increased to $5 \mathrm{~mm}$ and $10 \mathrm{~mm}$, respectively. Specimens are tested with the thermally loaded side facing down. On sandwich panels $(100 \mathrm{~mm} \times 400 \mathrm{~mm})$, the fire accelerant is applied on an area of $98 \mathrm{~mm} \times 98 \mathrm{~mm}$ at the center. Three $16.5 \mathrm{~mm}$ thick test specimen $(27 \mathrm{~mm} \times 394.6 \mathrm{~mm})$ are cut from a panel and investigated by a four-point bending test according to DIN 53293 [30] with the thermally loaded side facing up.

Ultrasonic scanning is performed according to EN 45000 with a USPC 3010-HFUS 2000 by DR. HILLGER equipped with a Panametrics $20 \mathrm{MHz}$ sensor head with a resolution of $2 \mu \mathrm{m}$. Changes in the composition of the polymer matrix due to the thermal load are analyzed by micro attenuated total reflection Fourier transform infrared spectroscopy ( $\mu$-ATR-FTIR). Spectra are recorded with a Bruker Tensor 27 spectrometer and a Harrick 
ATR cell equipped with a silicon crystal (diameter: $0.1 \mathrm{~mm}$ ) on the specimens' surface at positions given in Figure 3. Three spectra are recorded for every spot and the received band intensities are averaged.
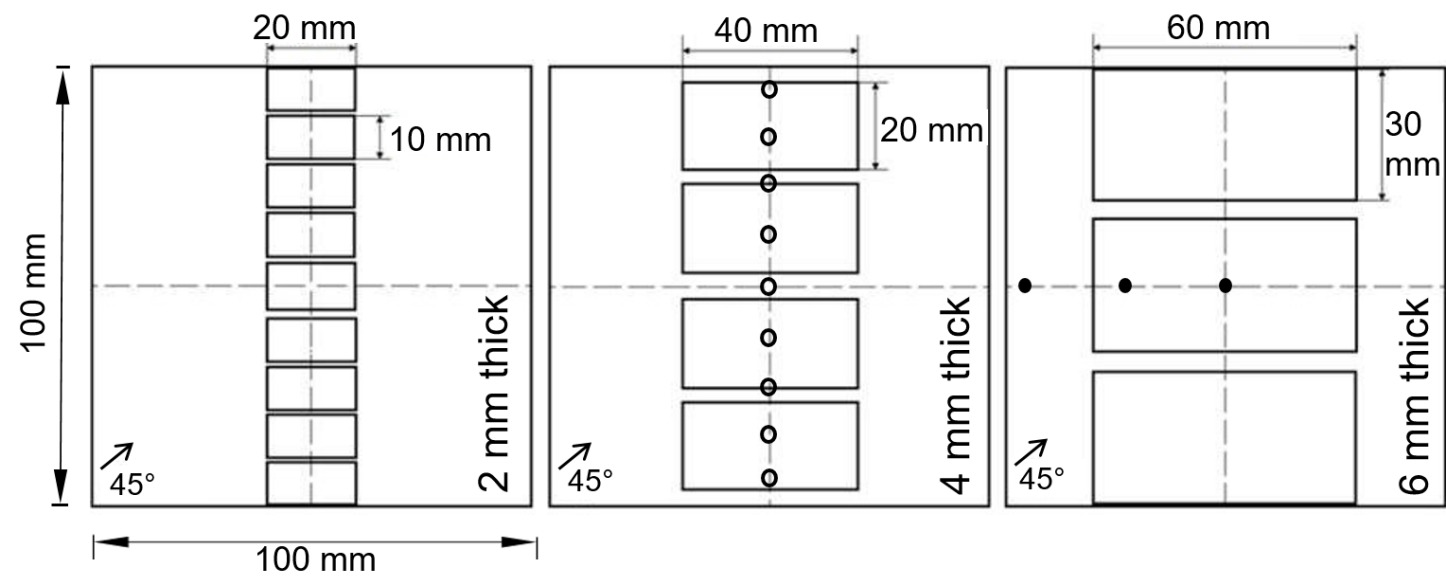

Figure 3. Size and position of the ILSS-specimens cut from the thermally loaded panels: o: represents the positions for the IR measurements (sample backside), $\bullet$ : positions of thermocouples (sample backside).

Temperatures are typically recorded with thermocouples (type K) attached to the front and back side of the samples using a picolog TC-08 data logger by pico technology, Germany.

\section{Results and Discussion}

\subsection{Preceding Large-Scale IID Fire Tests}

Figure 1 shows the setup and the beginning of a large-scale fire test with a $45^{\circ}$ tilt angle of the CFRP sample by high-speed camera images. Even though special care was taken to reproducibly perform these experiments, it can be clearly seen, that the amount of fire accelerant applied per area is hard to control. Bursting of the glass bottle spreads the fire accelerant randomly and variable amounts of the burning fire accelerant do not reach the CFRP. In order to improve the reproducibility of the experiments, most of them are carried out with horizontally aligned CFRP panels (see Table 1). A comparison of the results obtained for the horizontally and $45^{\circ}$ aligned panels, both $2 \mathrm{~mm}$ thick and 0.51 of fire accelerant are applied, shows, that the horizontally aligned CFRP panel is severely damaged, but the other one is not. Residual strength is reduced for the horizontally aligned panel ( $18 \%$ compared to initial value), the matrix is significantly degraded as indicated by infrared spectroscopy and pronounced delaminations are observed by ultrasonic testing. A possible explanation is that for a $45^{\circ}$ orientation of the panel a significant portion of the fire accelerant might be lost by dripping. However, for a horizontal alignment of the panel it is expected that not the hot upper part of the flame impinges the CFRP panel and thermal damage might not be pronounced.

However, still no basic correlations of the parameters are observed for horizontally applied panels. For example, the overall burning time differs significantly for repeated experiments with $4 \mathrm{~mm}$ thick panels ( $265 \mathrm{~s}$ and $585 \mathrm{~s}$ ). Figure 4 shows the temperature development for a horizontally aligned $4 \mathrm{~mm}$ thick panel during the test. Front side temperatures reach $600{ }^{\circ} \mathrm{C}$ and significantly differ at various places and test durations. Backside temperatures are considered reliable, whereas thermocouples at the front side may detach from the CFRP panel. Test durations determined by the presence of visually observable flames are not significant, as small remaining flames without considerable heat impact may falsify them. In Figure 4 it can be seen, that after $\sim 200 \mathrm{~s}$ the temperature maximum at the samples backside is reached, even though the fire accelerant does not extinguish until $585 \mathrm{~s}$ (see Table 1). 


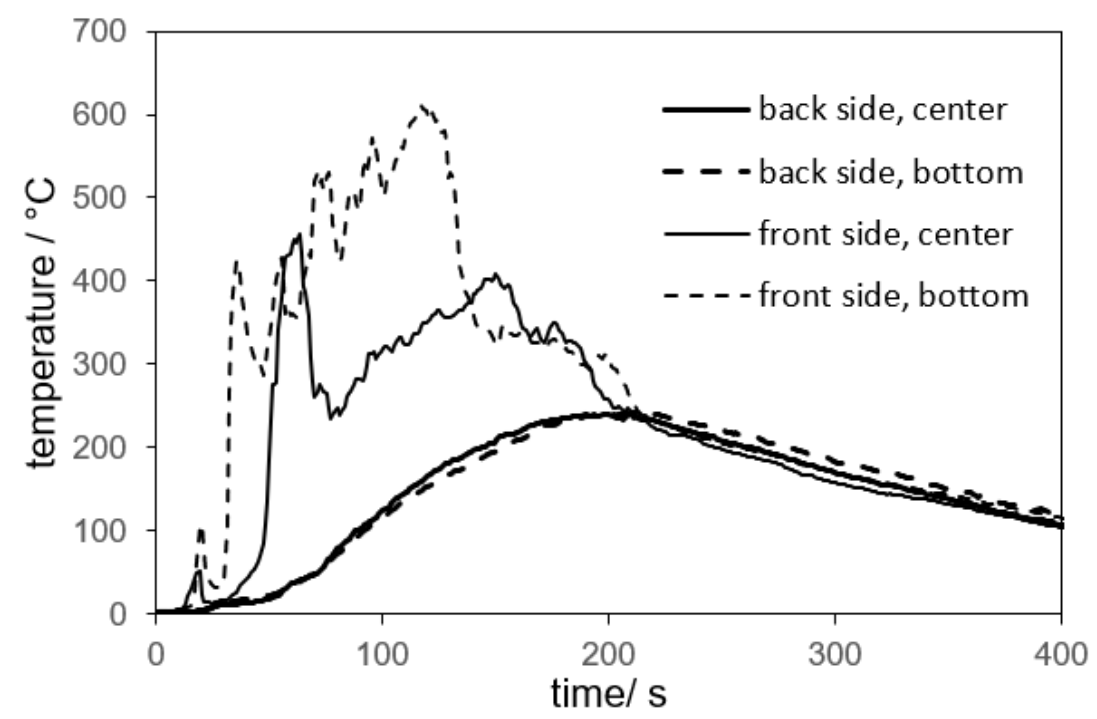

Figure 4. Temperature recordings for a large-scale IID fire test with a $4 \mathrm{~mm}$ thick horizontally aligned M18-1/G939 panel (see line 3 in Table 1).

The damage seems to be dependent on sample thickness. Even though one liter of fire accelerant is equally used for the 4 and $6 \mathrm{~mm}$ thick samples, the damages significantly differ. The $6 \mathrm{~mm}$ thick sample exhibits a thermal damage indicated by its mass loss of $\sim 3 \%$ instead of $0 \%$ for the $4 \mathrm{~mm}$ thick samples. Additionally it reaches higher temperatures at the samples' front side: $\sim 900^{\circ} \mathrm{C}$ instead of $600{ }^{\circ} \mathrm{C}$.

In summary, this type of experiment shows, that reproducible results are difficult to obtain. However, they proof that IID can destroy CFRP structures. For a systematic investigation, laboratory scale experiments are performed and described in the following. These laboratory experiments show similar amounts of applied fire accelerants per area, and similar developed temperatures and durations of burning. They are preferably carried out in horizontal alignment of the CFRP samples without dripping of burning fire accelerant. In order to avoid residues after the test by polystyrene in the fire accelerant, which falsify the determined mass loss of the CFRP, laboratory tests are performed without thickener.

This type of test guarantees reproducible results and simulates conditions of an IID assault with respect to a comparable way of heat impact in worst case.

\subsection{Laboratory Tests: Heat Release, Temperature Rise and Mass Loss Due to Combustion of Fire Accelerant}

Figure 5 shows representative heat release rate (HRR) curves obtained for the combustion of various amounts of fire accelerant on CFRP panels in a cone calorimeter (see Figure 2). They reach similar peak heat release rates, and the total heat release nearly lineary increases depending on the amount of fire accelerant (see also Figure 6). The burning time of the fire accelerant and therefore the duration of the conducted experiments also lineary increase by approx. $180 \mathrm{~s}$ per $10 \mathrm{~g}$ of applied fire accelerant in average. The averaged determined effective heat of combustion for all reference experiments is $42 \mathrm{~kJ} / \mathrm{g}$, which corresponds to the fuel load of hydrocarbons in the fire accelerant [31] and indicates a complete combustion of the fire accelerant during the experiment. For each amount of fire accelerant, the HRR curves are nearly identical for the various investigated horizontally aligned CFRP materials and the inert metal plate used as reference. 


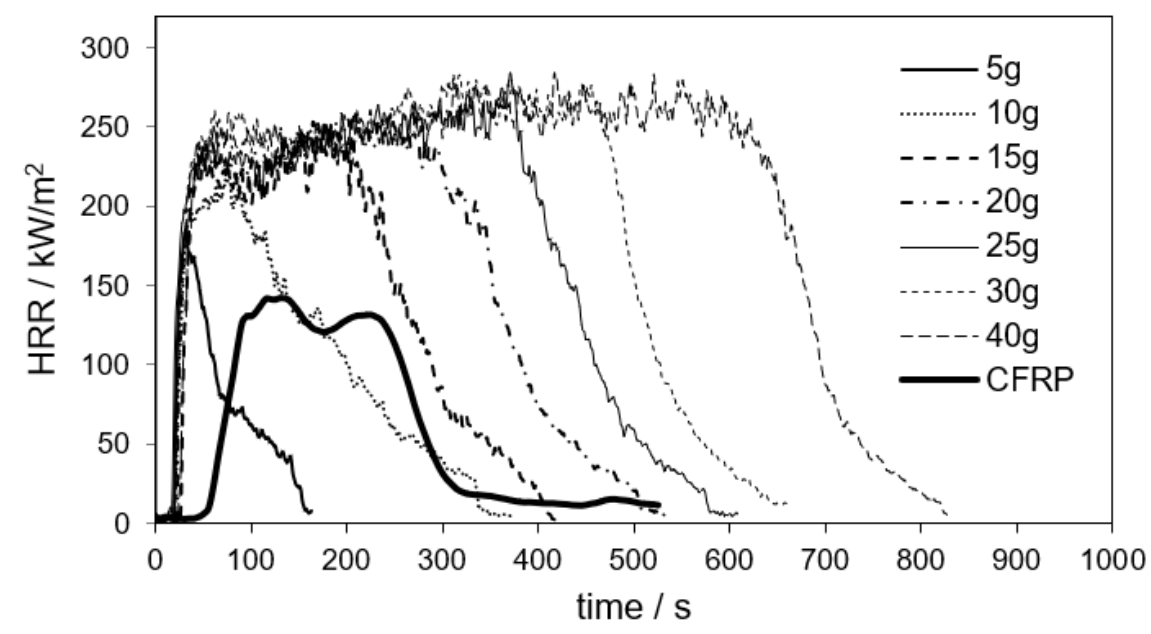

Figure 5. Exemplary heat release rate (HRR) curves for the combustion of various amounts of fire accelerant on CFRP samples. The HRR curve of the forced combustion of a $3 \mathrm{~mm}$ thick CFRP at an external heat flux of $60 \mathrm{~kW} / \mathrm{m}^{2}$ is added.

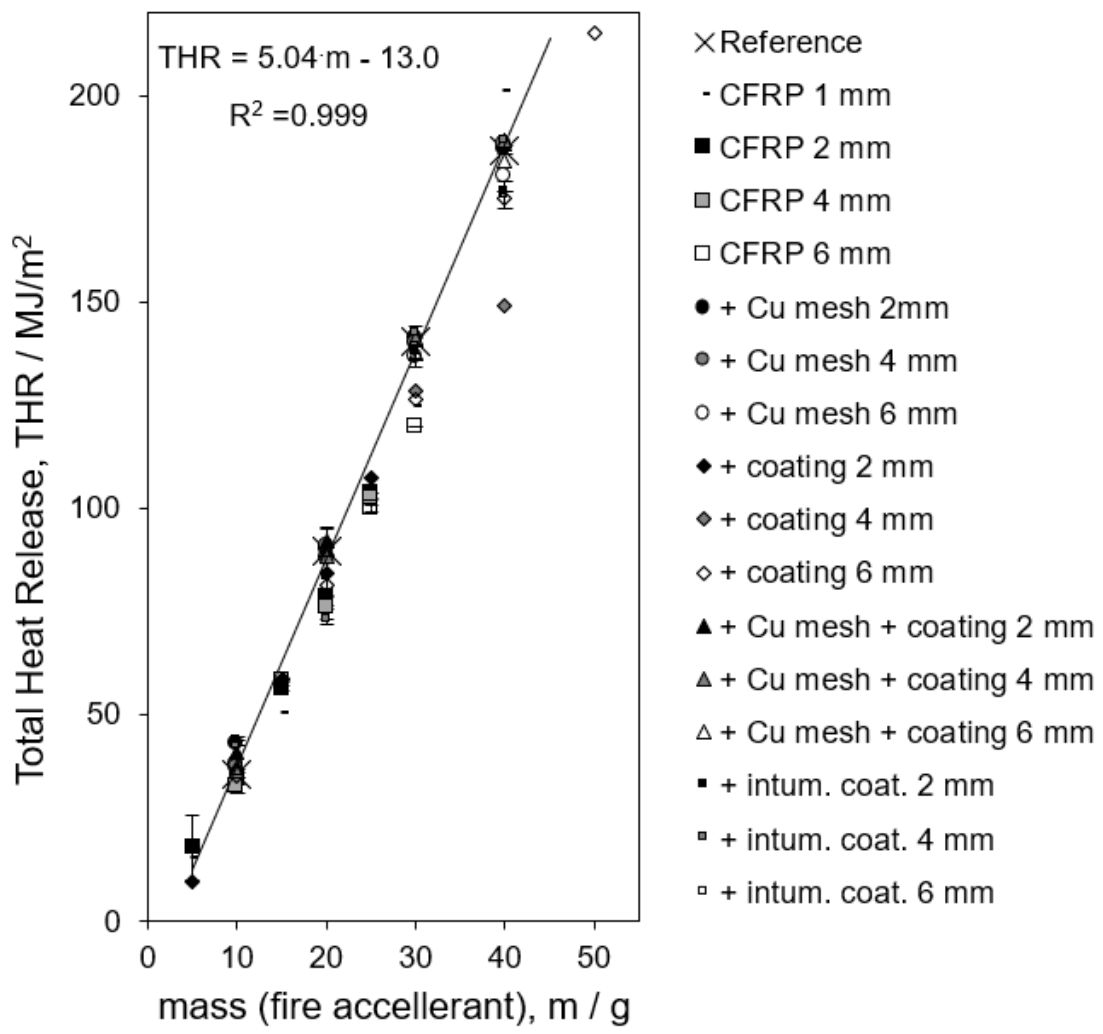

Figure 6. Total heat release (THR) for various amounts of fire accelerants on all types of horizontally aligned 8552/IM7 samples (Line corresponds to reference material: fire accelerant on steel panel).

Comparing the total heat releases for the combustion of the fire accelerants on various CFRP substrates with that of an inert metal plate (reference) in Figure 6 exhibits that in general no significant increase of the total heat release is observed due to a contribution by a combustion of the CFRP matrix or the coating. Only thin samples up to $2 \mathrm{~mm}$ partly indicate higher total heat releases than the reference experiments. However, the contribution is low. For some experiments, especially with coated $4 \mathrm{~mm}$ samples, the total heat releases are significantely lower than expected for the combustion of the fire accelerants. For these experiments it is assumed that little amounts of the fire accelerants were lost by leaking through the sample holder. 
For comparison reasons a typical HRR curve of the forced combustion of a $3 \mathrm{~mm}$ thick 8552/IM7 CFRP panel at an external heat flux of $60 \mathrm{~kW} / \mathrm{m}^{2}$ is added. For the forced combustion of this CFRP, a residue of $75 \%$ related to the initial mass is formed, and the total heat release is $25 \mathrm{MJ} / \mathrm{m}^{2}$ [20], for comparable $2 \mathrm{~mm}$ thick M18-1/G939 panels, a heat release of $25 \mathrm{MJ} / \mathrm{m}^{2}$ and a residue of $73 \%$ is determined [21]. The effective heat of combustion (related to mass of combusted material) of both CFRP is $\sim 22 \mathrm{~kJ} / \mathrm{g}$, which is typical for a combination of epoxy resin/polyethersulfon and epoxy resin/polyetherimide, respectively. The residue dominantely contains fibers and char. A detailed characterization of reaction-to-fire properties and the forced combustion of the two CFRP are reported in $[20,21]$.

In summary, the obtained heat release measurements are sensitive enough to measure a contribution by a combustion of the CFRP samples with a detection limit of about $5 \mathrm{MJ} / \mathrm{m}^{2}$, which, however, typically does not occur. Therefore, the conducted experiments dominantely focus on the heat impact of the fire accelerant on the CFRP and do not force a significant, exothermic combustion of horizontally aligned, thick CFRP panels.

The observed mass loss is below $1 \%$ for 4 to $8 \mathrm{~mm}$ thick samples and increases very slightly with the applied amount of fire accelerant (data not depicted). However, for $2 \mathrm{~mm}$ thick panels, a degradation of the polymer matrix close to the surface provides a higher ratio of the overall sample mass and the mass loss for pure 8552/IM7 linearly increases up to $5 \%$ for $30 \mathrm{~g}$ fire accelerant. The highest mass loss of $7.5 \%$ for horizontally aligned panels is reached by a $1 \mathrm{~mm}$ thick M18-1/G939 sample after an impact of $30 \mathrm{~g}$ fire accelerant.

In summary, the determined mass loss increases with the amount of fire accelerant, and decreases with sample thickness, which was also observed for irradiation experiments [17], but it is too low causing an additional significant heat release by a pronounced exothermic combustion of resin matrix for samples thicker than $2 \mathrm{~mm}$ (see above).

Temperature necessary for ignition of 8552/IM7 was observed to be in the range of $400{ }^{\circ} \mathrm{C}$ at the surface of the irradiated side by cone calorimetry [20]. A determination of the temperature is however inaccurate by thermocouples at the front surface of the CFRP panel during combustion of the fire accellerant, because it may detach. Therefore, the temperature trace at the front side of a $4 \mathrm{~mm}$ thick panel with $20 \mathrm{~g}$ of applied fire accellerant (Figure 7A) shows a wide variation for the reached maximum temperature, which reaches $500{ }^{\circ} \mathrm{C}$ instead of $390^{\circ} \mathrm{C}$ in repeated experiments. In contrast, the temperature traces recorded at the backside are accurate and indicate higher temperatures at the center $\left(275^{\circ} \mathrm{C}\right)$ of the specimen compared to the areas close to its edges $\left(218^{\circ} \mathrm{C}\right)$. Additionally it takes slightly longer to reach the maximum temperatures at the edge of the sample compared to the center (400 s instead of $370 \mathrm{~s}$ ). Both observations are to be expected for the formation of a cone shaped flame above the panel (see Figure 2) and the heat conduction by the metal frame of the sample holder.

Time to reach maximum backside temperature increases strongly with the increasing amounts of fire accelerant, as its combustion takes longer (see also Figure 5). However, these times increase only slightly with increasing panel thickness (Figure 7B). For example, maximum temperature is reached after $132 \mathrm{~s}$ when $10 \mathrm{~g}$ of fire accelerant is applied on a $2 \mathrm{~mm}$ panel, and after only $209 \mathrm{~s}$ when a $6 \mathrm{~mm}$ panel is investigated, but after $730 \mathrm{~s}$ when $40 \mathrm{~g}$ are applied on a $2 \mathrm{~mm}$ thick panel. The higher heat capacities of thicker samples and the longer duration of heat transfer are responsible for these observations, respectively. Also maximum backside temperatures increase with the amount of fire accelerant. For example, a temperature of $279^{\circ} \mathrm{C}$ is reached for $10 \mathrm{~g}$ of fire accelerant, and $321^{\circ} \mathrm{C}$ for $40 \mathrm{~g}$ on $2 \mathrm{~mm}$ thick samples. For $6 \mathrm{~mm}$ thick samples, these temperatures are lower: $195^{\circ} \mathrm{C}$ for $10 \mathrm{~g}$ and $269^{\circ} \mathrm{C}$ for $40 \mathrm{~g}$, respectively. The temperature differences between 2 and $6 \mathrm{~mm}$ thick samples, for a certain amount of fire accelerant, is more pronounced for small amounts of fire accelerant $\left(10 \mathrm{~g}: 84^{\circ} \mathrm{C} ; 40 \mathrm{~g}: 52{ }^{\circ} \mathrm{C}\right)$, indicating especially low backside temperatures for thicker samples and therefore more pronounced temperature gradients. In Figure 7B, a remarkable unsteady temperature increase is observed for $2 \mathrm{~mm}$ thick samples and masses of fire accelerants more than $20 \mathrm{~g}$. An occurring intermediate temperature drop 
is correlated to a pronounced matrix degradation and is typically indicated by large areas of free carbon fibers in pictures of the panels' surface after the experiment. The reasons are a combination of pronounced delaminations with a retarded heat transfer to the samples backside and the endothermic pyrolysis of the matrix (see below).
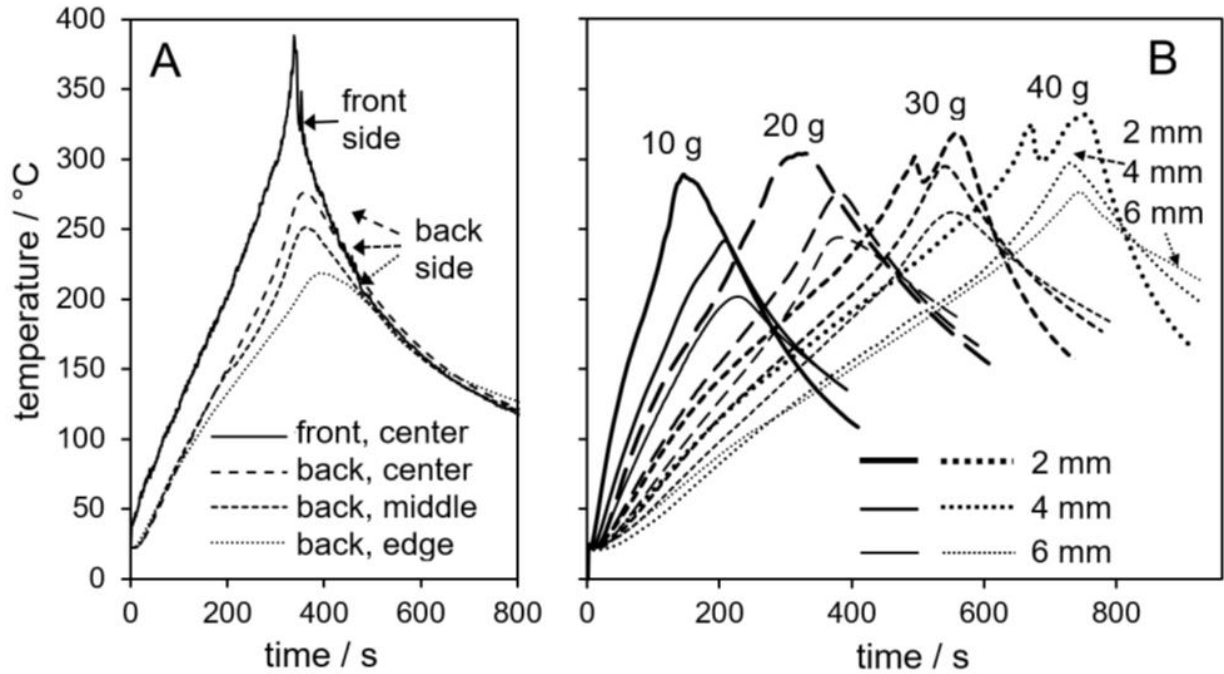

Figure 7. Exemplary temperature rises on 8552/IM7 CFRP panels (with integrated copper mesh and applied coating). (A) at various positions on a $4 \mathrm{~mm}$ thick panel for $20 \mathrm{~g}$ of fire accelerant (exact positions see Figure 3 (B) at the center of the backside of various thick panels and amounts of fire accelerant.

Figure 8 shows the temperatures in various depths inside $4 \mathrm{~mm}$ thick panels during the combustion of $40 \mathrm{~g}$ fire accelerant. Temperatures nearly linearly increase throughout the intact sample with only a slight gradient into the depth until a rapid temperature rise occurs after $640 \mathrm{~s}$ for 8552/IM7. At the same time of the rapid temperature increase in areas close to the surface, a temperature drop occurs underneath. This phenomenon is typical for the formation of delaminations. Delaminations of the top plies provide a barrier for the heat transfer into the bulk material and promote the degradation of the top plies [32]. A rapid temperature increase also indicates that the pyrolysis zone may have reached the depth of the thermocouple [20]. After $640 \mathrm{~s}$, the degradation of the polymer matrix reaches a depth of $1 \mathrm{~mm}$. Underneath the first ply $(0.1 \mathrm{~mm})$ a temperature of $310^{\circ} \mathrm{C}$ is reached. For depths from 1 to $2 \mathrm{~mm}$ a shift of $\sim 40 \mathrm{~s}$ for the beginning rapid temperature increase is observed, which corresponds to an average migration velocity of the pyrolysis zone of $\sim 25 \mu \mathrm{m} / \mathrm{s}$. For the forced combustion of $4 \mathrm{~mm}$ thick QI 8552/IM7 samples at $60 \mathrm{~kW} / \mathrm{m}^{2}$, a similar migration velocity of the pyrolysis zone of $35 \pm 3 \mu \mathrm{m} / \mathrm{s}$ was reported [20].

Matrix degradation is less pronounced in areas deeper than $2 \mathrm{~mm}$, since the temperature rises are lower and only maximum temperatures of $300{ }^{\circ} \mathrm{C}$ are reached. With a maximum temperature of $495^{\circ} \mathrm{C}$ at a depth of $0.1 \mathrm{~mm}$, degradation of the matrix close to the surface is evident. The contribution of the matrix degradation to the total heat release during the application of the fire accelerant is not significant. Therefore, matrix degradation is considered to have predominantly pyrolysis instead of self-sustaining oxidative and exothermic character. As mass loss is $\sim 1 \%$ only, no significant contribution to the overall heat release is measured and temperature rises inside the CFRP material are mainly induced by the burning fire accelerant. 


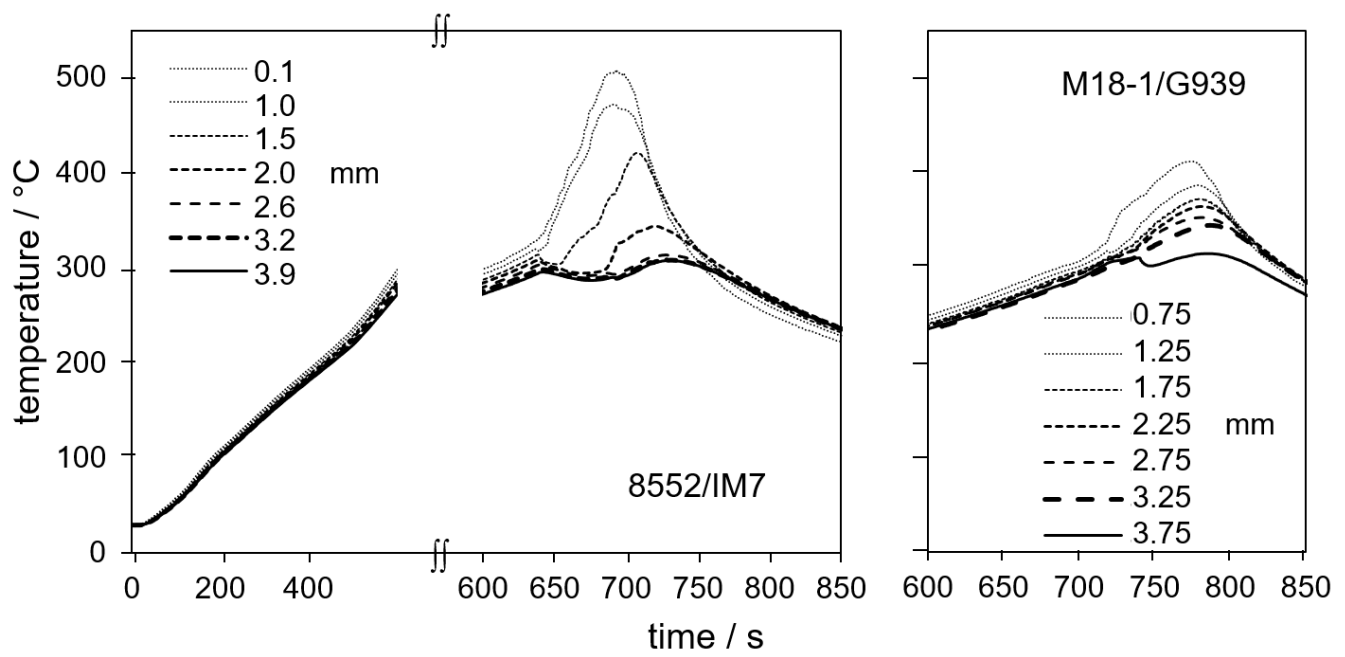

Figure 8. Exemplary temperature rises in various depth of $4 \mathrm{~mm}$ thick 8552/IM7 and M18-1/G939 CFRP panels with integrated thermocouples during application of $40 \mathrm{~g}$ fire accelerant.

After flame out, the surface cools fastest, as indicated by the lowest temperatures of the thermocouple in a depth of $0.1 \mathrm{~mm}$.

Similar effects are observed for M18-1/G939. However, effects by delaminations are less pronounced for the fiber fabric reinforcement [21], and M18-1/G939 has a slightly higher heat capacity than 8552/IM7 [17], explaining the longer duration ( 720 s) until a rapid temperature increase occurs. The presence of the flame retardants may play an additional role.

\subsection{Non-Destructive Testing after Thermal Loading}

\subsubsection{Visual Inspection}

Figure 9 shows representative cross sections and photographs of the treated front side of selected M18-1/G939 samples after the impact of various amounts of fire accelerant. For $2 \mathrm{~mm}$ thick samples a very fast transition from nearly intact material (after application of $5 \mathrm{~g}$ of fire accelerant with only slightly darker areas in the center of the panel) to severely damaged samples is observed. After application of $10 \mathrm{~g}$ of fire accelerant, delaminations can be found throughout the whole thickness of the sample even if matrix degradation at the surface of the treated side is hardly visible. This transition is not accompanied by a significant increase in mass loss $(\sim 0.5 \%)$. Therefore, thermally induced strain is responsible for this step of damage. With higher amounts of fire accelerant $(15 \mathrm{~g})$, carbon fibers are set free at the treated side after the matrix is decomposed and the number of delaminations increases. For $30 \mathrm{~g}$ of fire accelerant, the matrix is degraded also in deeper areas of the panel. Therefore, mass loss increases significantly from $1.2 \%$ to $5 \%$ and a large area of free carbon fibers at the treated surface are observed. Formed delaminations close to the treated side provide a protection for intact material underneath and the panels significantly expand. These effects are more pronounced for thicker samples. For $6 \mathrm{~mm}$ thick samples the major portion of the cross section remains intact and delaminations are visible only close to the treated side. For a comparable damage between $2 \mathrm{~mm}$ and $6 \mathrm{~mm}$ thick samples, far higher amounts of fire accelerant are necessary for the thick samples. Whereas for $2 \mathrm{~mm}$ thick samples, large areas show uncovered carbon fibers at the surface for $15 \mathrm{~g}$ of fire accelerant, $6 \mathrm{~mm}$ thick samples start to exhibit a comparable matrix degradation not until $30 \mathrm{~g}$. Again, the higher heat capacities of thicker samples are responsible for the retarded damage initiation. 


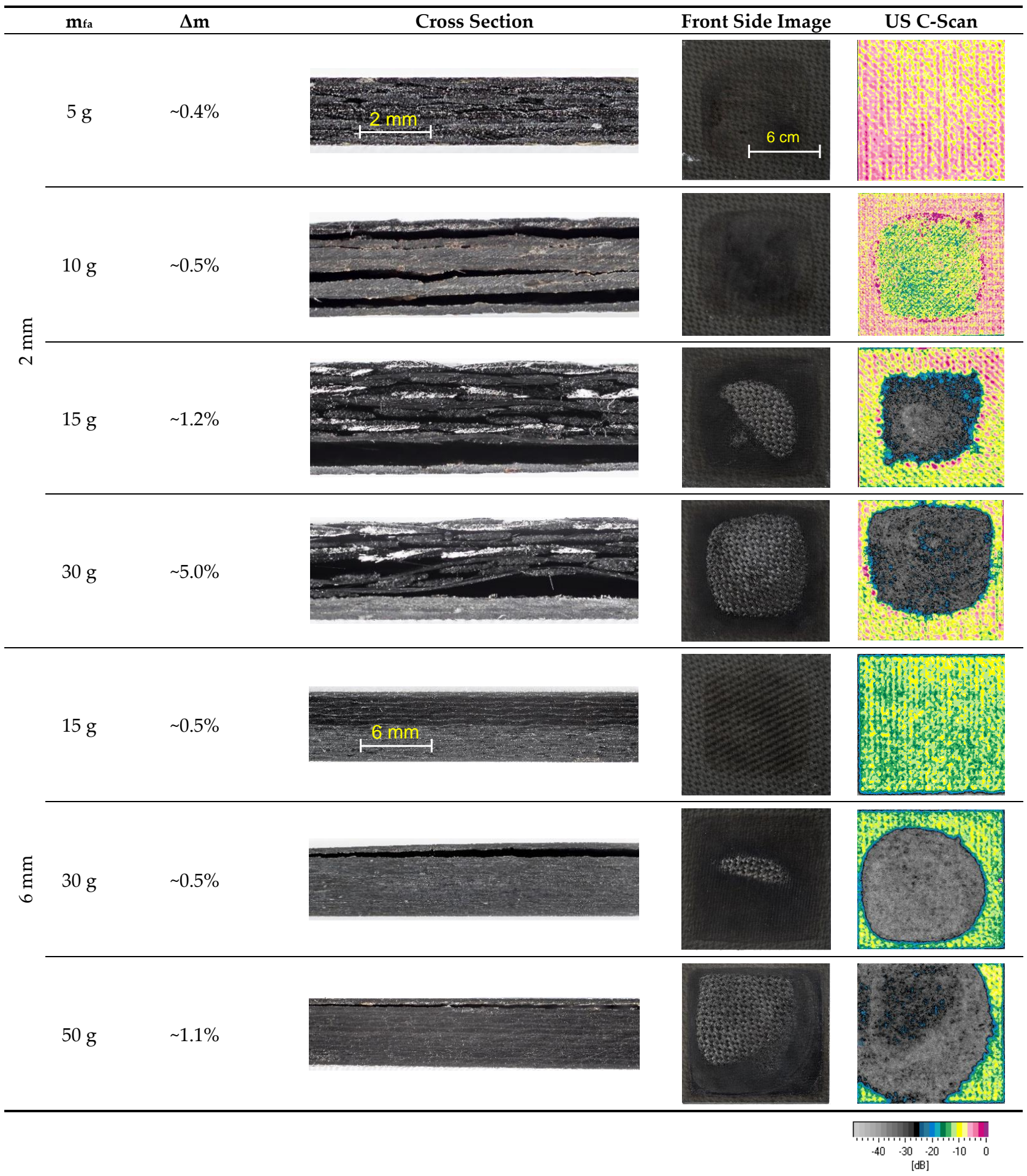

Figure 9. Cross sections (hot side on top), photographs and ultrasonic C-scans of 2 and 6 mm thick M18-1/G939 panels after impact of various amounts of fire accelerant. Mass loss $(\Delta \mathrm{m})$ is additionally given.

\subsubsection{Ultrasonic Testing}

As a routine non-destructive technique, ultrasonic C-scans are performed for all investigated specimen (see exemplarily Figure 9). For a moderate thermal load after application of $5 \mathrm{~g}$ fire accelerant, no damage is detected on $2 \mathrm{~mm}$ thick M18-1/G939 samples. Beginning from $10 \mathrm{~g}$, occurring delaminations are responsible for increasingly damaged areas in the C-scans, even if matrix degradation is hardly observed at the surface. 
For the $6 \mathrm{~mm}$ thick sample, more than $15 \mathrm{~g}$ of fire accelerant is necessary to detect a damage by ultrasonic testing, as thicker samples are less damaged (see above). The ratio of damaged area in the ultrasonic C-scans correlates with the amount of applied fire accelerant (data not depicted). Similar data are obtained for 8552/IM7 samples.

In summary, ultrasonic testing is a suitable technique to identify thermal damage by improvised fire accelerants. Only for moderate damages it is not sensitive enough. Here, infrared spectroscopy provides a more sensitive alternative.

\subsubsection{Infrared Spectroscopy}

An IR-spectroscopic analysis of the 8552 matrix system shows intensive bands at $1510 \mathrm{~cm}^{-1}$ and at $1486 \mathrm{~cm}^{-1}$, which are attributed to epoxy resin (EP) and polyethersulfone (PES), respectively [23,33]. Figure 10 depicts that thermal degradation of the EP resin is preferred over the thermoplastic toughener PES, as the EP resin is thermally less resistant and indicated by a loss of intensity for the band at $1510 \mathrm{~cm}^{-1}$, recorded in the hotter center of a specimen (spectrum at $50 \mathrm{~mm}$ ) compared to the edges.
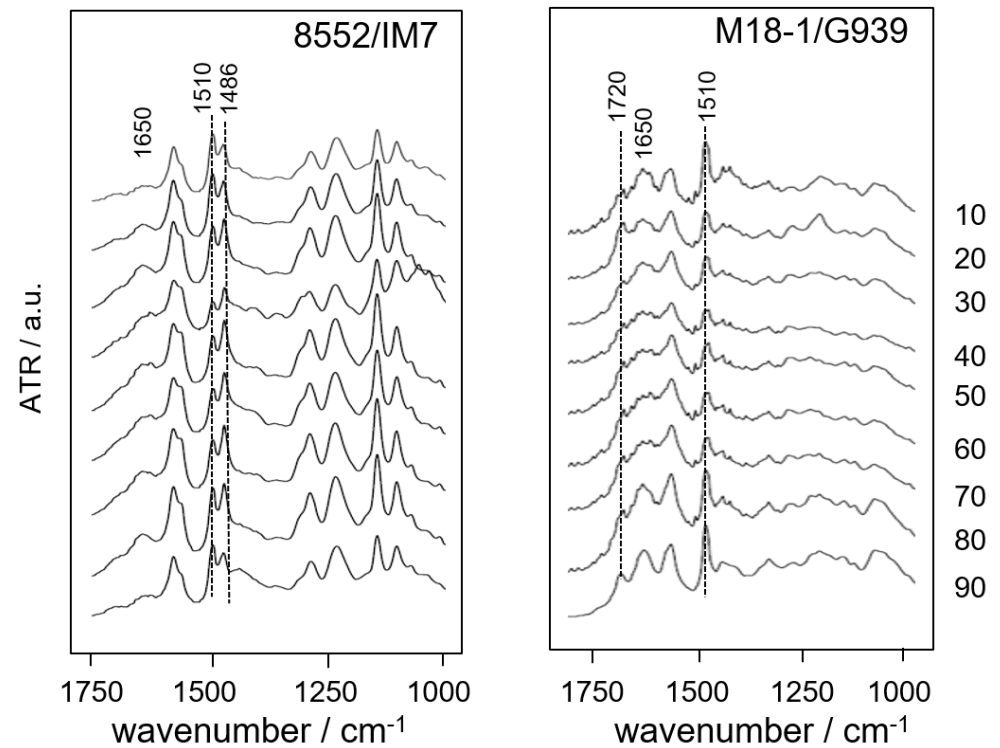

Figure 10. ATR-FTIR-spectra recorded along the middle of the backside (given distance from the edge in mm, see Figure 3) of 2 mm thick 8552/IM7 (left) and M18-1/G939 (right) specimens with marked characteristic bands for EP $\left(1510 \mathrm{~cm}^{-1}\right)$, PES $\left(1486 \mathrm{~cm}^{-1}\right)$, and PEI $\left(1720 \mathrm{~cm}^{-1}\right)$ after impact of $10 \mathrm{~g}$ fire accelerant (spectra are vertically shifted).

An IR-spectroscopic analysis of M18-1/G939 is based on a band at $1720 \mathrm{~cm}^{-1}$, which is characteristic for polyetherimide (PEI) as toughener [34]. Again, the band at $1510 \mathrm{~cm}^{-1}$ originates from the epoxy resin. With increasing thermal degradation a decrease of the epoxy band with respect to the polyetherimide band can be observed, similar to the behavior of the 8552 matrix. For both materials, oxidation of the polymer matrix is indicated by surface carbonyl species with a broad band in the range of $1650 \mathrm{~cm}^{-1}[35,36]$.

Thermal degradation of the polymer matrix is characterized by the intensity ratio of IR-bands at $1510 \mathrm{~cm}^{-1}$ (EP) and at $1486 \mathrm{~cm}^{-1}$ (PES) [18] for 8552/IM7, as well as $1510 \mathrm{~cm}^{-1}$ (EP) and $1720 \mathrm{~cm}^{-1}$ (PEI) for M18-1/G939.

Figure 11 exemplarily shows the matrix degradation by means of profiles of this band intensity ratio through the middle (see Figure 2) of the specimens' backside, dependent on the amount of fire accelerant and sample thickness. For 8552/IM7 the intensity ratio is slightly above 1 for an intact sample and decreases with increasing thermal damage. With increasing amounts of fire accelerant this ratio decreases especially for the $2 \mathrm{~mm}$ specimens and a pronounced difference between the hotter centers of the specimen $(=50 \mathrm{~mm}$ position) and the colder edges is observed. For a certain amount of fire accelerant, matrix 
degradation is more pronounced for thinner samples. For example, to reach a matrix degradation indicated by a band intensity ratio of roughly 0.8 at the center of the samples backside, $10 \mathrm{~g}$ of fire accelerant is necessary for the $2 \mathrm{~mm}$ thick specimen, whereas $30 \mathrm{~g}$ are necessary for the $4 \mathrm{~mm}$ thick specimen. As the reached maximum temperatures are lower for thicker samples (see Figure 7), matrix degradation is less pronounced at the samples backside. No spectra are obtained at the sample's front side of the panels due to contamination of the surface by residues of combustion.
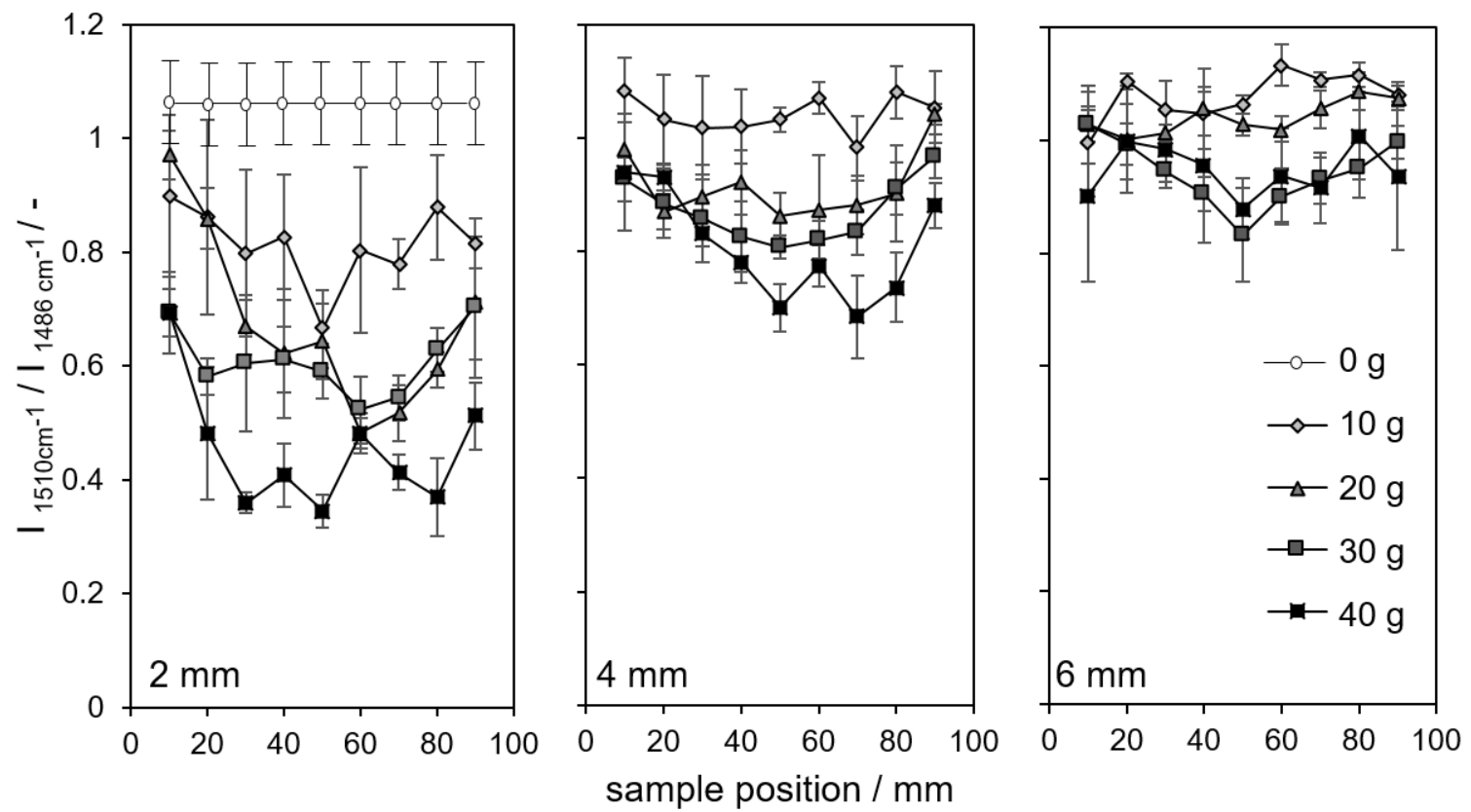

Figure 11. Representative distribution of the intensity ratios of bands characteristic for EP $\left(1510 \mathrm{~cm}^{-1}\right)$ and PES $\left(1486 \mathrm{~cm}^{-1}\right)$ after impact of various amounts of fire accelerants on 2, 4, and $6 \mathrm{~mm}$ thick 8552/IM7 samples (with integrated copper mesh), recorded at the backsides (horizontally aligned).

The same observations are made for the M18-1/G939 samples by means of the IR band intensity ratio $\mathrm{I}_{1510 \mathrm{~cm}^{-1}} / \mathrm{I}_{1780 \mathrm{~cm}^{-1}}$ (data not depicted). For a comparison of the efficiency of various protective measures, specimen at the center of the panel with lowest band intensity ratios are selected (see below).

\subsection{Residual Interlaminar Shear Strength (ILSS)}

Residual ILSS of composite samples with an integrated copper mesh after impact of various amounts of fire accelerant is exemplarily shown in Figure 12. According to matrix degradation measured by IR spectroscopy, ILSS shows lower values in the center of the samples, compared to the edges and its decrease is more pronounced for thin samples with increasing amounts of fire accelerant. For $6 \mathrm{~mm}$ thick samples only three test specimen can be gained from the panel, and measuring the lateral distribution of the damage is limited. Thick samples show a less pronounced and continuous decrease of residual strength compared to the thin ones. Whereas the ILSS decreases only by approx. $20 \%$ for the application of $40 \mathrm{~g}$ of fire accelerant for $6 \mathrm{~mm}$ samples, the $2 \mathrm{~mm}$ specimen does not retain a significant residual ILSS. In this case, samples with residual ILSS below roughly $30 \mathrm{~N} / \mathrm{mm}^{2}$ tend to fail in multiple plies, as pronounced delaminations occur throughout the thickness (see Figure 9). Samples with plies falling apart before testing are attributed to a residual strength of $0 \mathrm{~N} / \mathrm{mm}^{2}$. In Table 2 it is obvious, that $1 \mathrm{~mm}$ thick panels lose their mechanical integrity for very low amounts of fire accelerant. The $8 \mathrm{~mm}$ thick panels withstand typical amounts of fire accelerants in an arson attack, as unrealistically high amounts are necessary for a severe damage. For a comparison of the efficiency of various 
protective measures, specimen at the center of the panel with the lowest residual strength are selected (see below and Table 2).
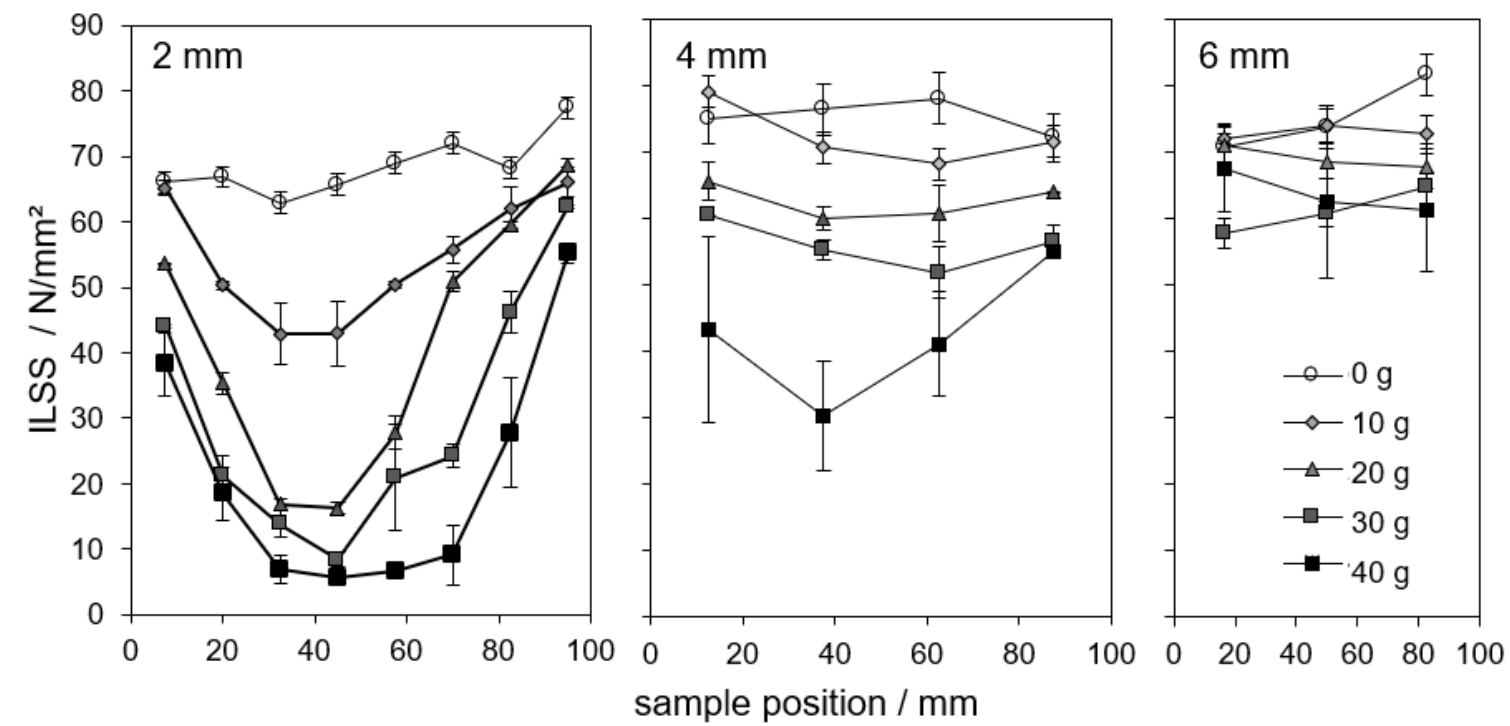

Figure 12. Representative distribution of interlaminar shear strength (ILSS) after impact of various amounts of fire accelerants on 2, 4, and $6 \mathrm{~mm}$ thick 8552/IM7 samples (with integrated copper mesh, horizontally aligned).

\subsection{Influence of Horizontal and Vertical Alignment of the Panels}

A vertical alignment of the sample at the edge of the sample holder leads to different areas of thermal damage compared to the horizontally aligned panel. In an upright position, the top part of a $2 \mathrm{~mm}$ thick 8552/IM7 panel is visually more damaged, as shown in Figure 13, as the flame of the burning fire accelerant may be higher than the panel $(10 \mathrm{~cm})$, and hotter areas of the flame have impact on the panel. Therefore, thermal damage is not distributed symmetrically over the panel, but larger at the top compared to the horizontally aligned panels, as also indicated by ultrasonic testing. Correspondingly, residual interlaminar shear strength decreases continuously and rapidly from bottom to top for masses of fire accelerant higher than $15 \mathrm{~g}$ (see Figure 13). Minimum residual ILSS is nearly similar for a horizontal and vertical alignment of the 8552/IM7 panels, when the center of the samples is considered (see Table 2). For M18-1/G939, $10 \mathrm{~g}$ of fire accelerant is sufficient to reduce the residual strength to $0 \mathrm{~N} / \mathrm{mm}^{2}$ for vertically aligned panels, whereas horizontally aligned panels retain a residual strength of $31 \%$. However in the top part, residual ILSS is significantly lower for vertically aligned panels. The reason for these observations is a more pronounced matrix degradation and combustion, as indicated by the heat release rate curves in Figure 14. Vertically aligned samples show a prolonged heat release compared to the horizontally aligned. In contrast to horizontally aligned samples, shown in Figure 6, an additional contribution to the total heat release by the combustion of the matrix is indicated, as seen Figure 14 (inset A). A maximum contribution of approx. $30 \mathrm{MJ} / \mathrm{m}^{2}$ for the $8552 / \mathrm{IM} 7$ sample investigated with $40 \mathrm{~g}$ fire accelerant is in the range of the total heat release for the forced combustion of the CFRP (see above). Correspondingly, mass loss linearly increases with increasing amounts of fire accelerant and is higher for vertically than for horizontally aligned samples (see inset B in Figure 14). For example, a $2 \mathrm{~mm}$ thick M18-1/G939 sample reaches a mass loss of $17.5 \%$ for the application of $50 \mathrm{~g}$ of fire accelerant. For a forced combustion, a typical mass loss of $25 \%$ is observed (see above). Thus, these samples investigated in a vertical alignment are partly combusted and do not retain a significant residual strength, as it is also observed for samples after a forced combustion. In the upright position of the panels, the barrier effects of the carbon fiber for combustion are less pronounced. Matrix degradation and combustion are favored parallel to the fibers (wick effect) [37], and access of air is less hindered. 

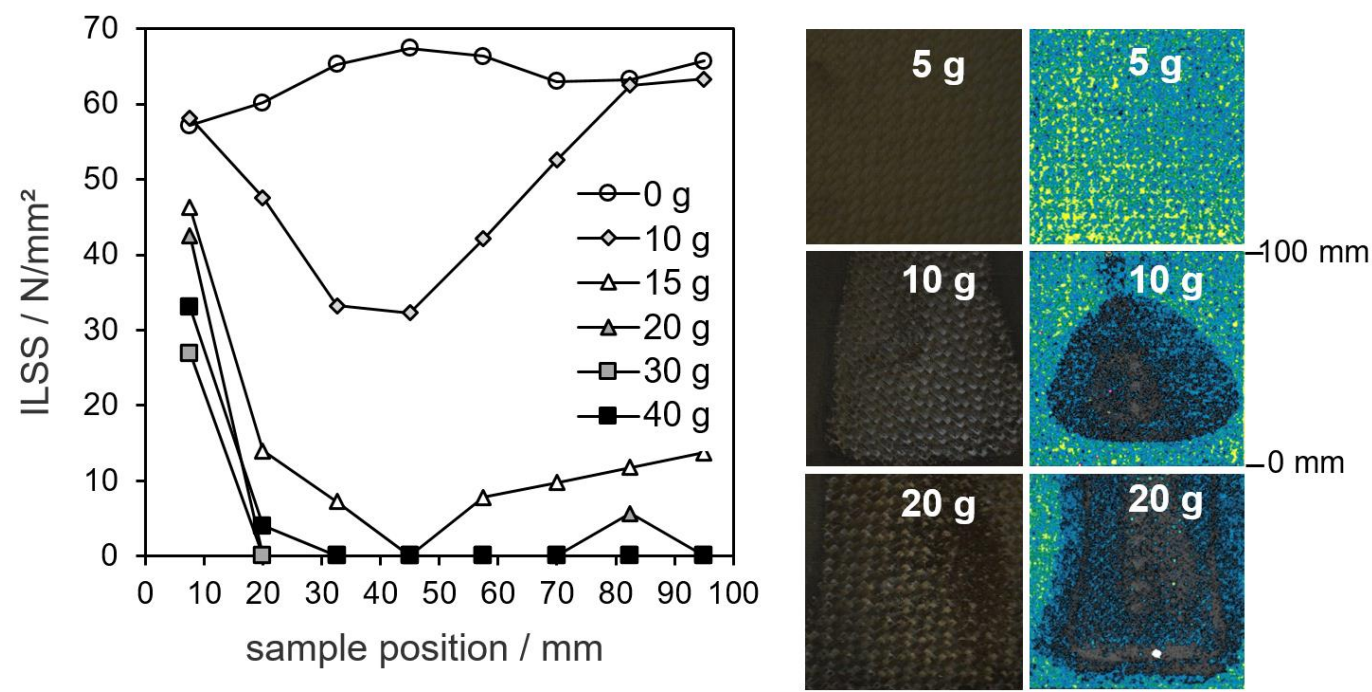

Figure 13. Representative distribution of interlaminar shear (ILS) strength and corresponding ultrasonic scans after the impact of various amounts of fire accelerants on vertically aligned $2 \mathrm{~mm}$ thick 8552/IM7 samples.

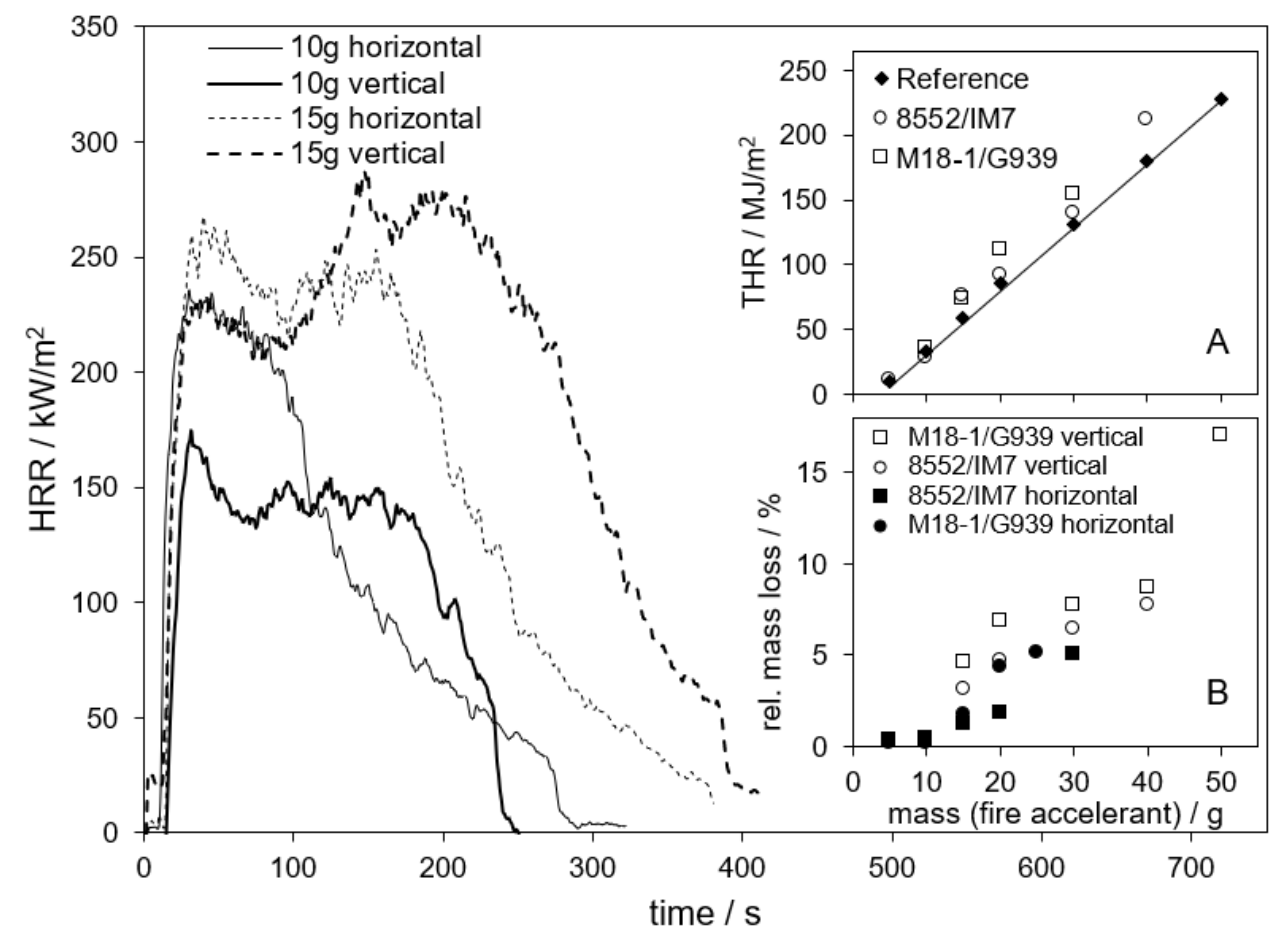

Figure 14. Heat release rates (HRR) and total heat release (THR, inset A) for $2 \mathrm{~mm}$ thick horizontally and vertically aligned 8552/IM7 samples as well as mass loss (inset B) for various amounts of fire accelerants. Line in inset A corresponds to the reference material without CFRP (steel panel). (HRR curves of reference measurements correspond to those of horizontally aligned CFRP panels).

\subsection{Sandwich Samples}

A $16.5 \mathrm{~mm}$ thick sandwich sample with $1 \mathrm{~mm}$ thick M18-1/G939 CFRP skins is investigated applying up to $20 \mathrm{~g}$ of fire accelerant in an area of $98 \mathrm{~mm} \times 98 \mathrm{~mm}$ at the center of the panel. Figure 15 shows the force at break in a four point bending test, which dramatically decreases even for low amounts of fire accelerant. For $10 \mathrm{~g}$, a residual force of $6 \%$ is observed, when compared to the initial force. Corresponding to the weakest residual mechanical performance of thin monolithic panels (see Table 2), sandwich panels 
with thin CFRP skins are prone to severe damage by improvised fire accelerants. Failure mode is represented by the loss of adhesion of the thermally loaded CFRP skin to the honeycomb core and its deformation during destructive testing (sketch in Figure 15). Also the honeycomb core is thermally damaged as indicated by the color change from orange to black close to the upper side.

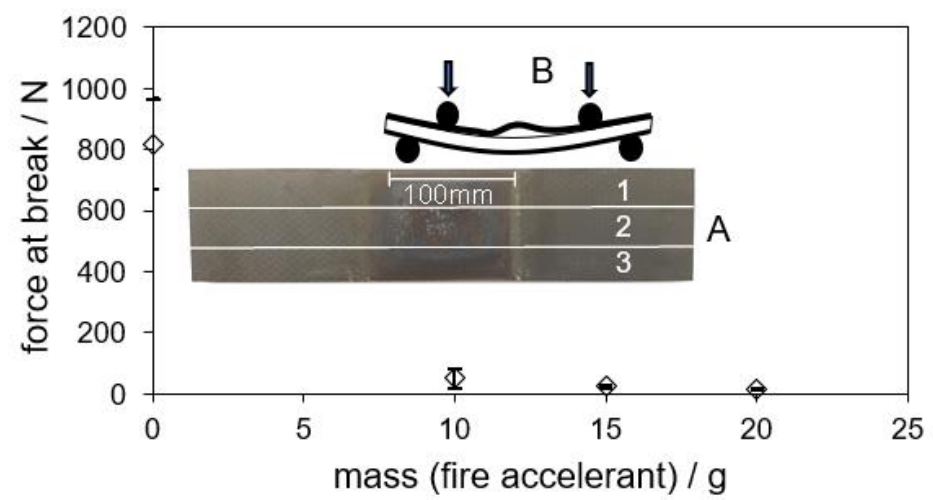

Figure 15. Force at break in a four-point bending test of sandwich panels made of the material M18-1/G939 after impact of various amounts of fire accelerant. Each data point represents the average of three tested specimen at position 1, 2, 3 (A) Sketch (B) represents typical failure mode with the thermally treated side on top.

\subsection{Evaluation of Protective Measures}

In order to represent the realistic conditions of a vehicle or aircraft, samples with various coatings and protective layers are prepared. A typical top coat for military aircraft, a copper mesh used for protection against lightning strike, a combination thereof, and a typical commercial intumescent coating are additionally applied.

Figure 16 illustrates a selection of samples after application of $40 \mathrm{~g}$ fire accelerant on $2 \mathrm{~mm}$ thick samples. The intumescent coating forms a char residue, which is $\sim 0.5 \mathrm{~cm}$ thick after the experiment (Figure 16A). The formed char can be easily removed (Figure 16B), but it provides an effective protection for the CFRP material, as can be seen by the corresponding ultrasonic C-scan (Figure 16C). No delaminations are observed in contrast to the samples with a copper mesh or an additional top coat (Figure 16D-G). Even though residues of the top coat in terms of the silicate filler remain, no pronounced protective effect is indicated by the ultrasonic C-scan. The copper mesh alone expectedly shows a similar damage.

Figure 17A shows the minimum interlaminar shear strength (ILSS) after impact of various amounts of fire accelerants on 2, 4, and $6 \mathrm{~mm}$ thick 8552/IM7 samples with various protective measures. The minimum residual strength after impact is typically reached at the center of the panel. For the $2 \mathrm{~mm}$ thick samples, a significant influence of the various protective measures is observed. Whereas the sole CFRP and the coated CFRP decrease rapidly and similarly in residual ILSS, samples with integrated copper mesh, with and without coating, retain a residual ILSS after impact of up to $40 \mathrm{~g}$ fire accelerant. However, samples are severely degraded and fail within several plies during mechanical testing. The third group of data, indicated by lines in Figure 17A, represent $2 \mathrm{~mm}$ thick samples protected by an intumescent coating. The intumescent coating provides the best protection (see above). A comparison for the impact of $20 \mathrm{~g}$ fire accelerant, shows exemplarily no residual strength for coated or uncoated CFRP, $15 \%$ residual strength for the samples containing a copper mesh and $60 \%$ for the sample protected with an intumescent coating. 

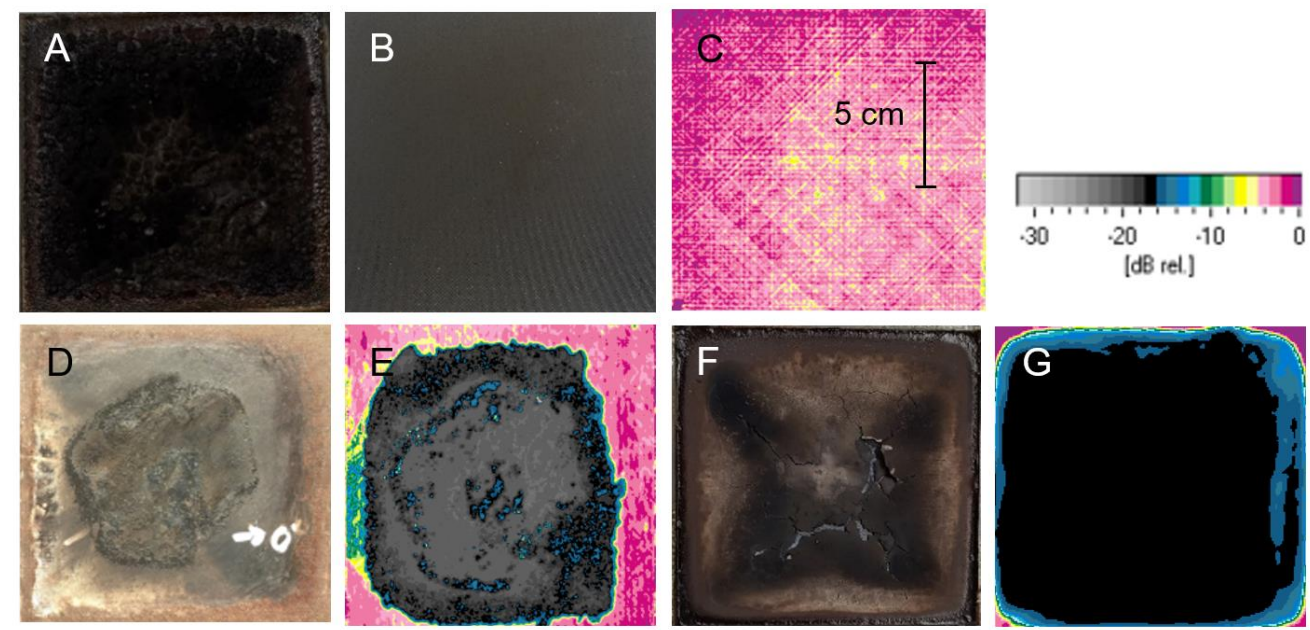

Figure 16. $2 \mathrm{~mm}$ thick 8552/IM7 samples after impact of $40 \mathrm{~g}$ fire accelerant: (A) CFRP with intumescent coating, (B) after removing the residues of the intumescent coating, (C) corresponding ultrasonic C-scan, (D) CFRP with copper mesh, (E) corresponding ultrasonic C-scan, (F) CFRP with copper mesh and coating, (G): corresponding ultrasonic C-scan.

Samples thicker than $2 \mathrm{~mm}$ retain higher residual strength, which is highest for $6 \mathrm{~mm}$ samples within this comparison. For example, the pure CFRP shows no residual strength for the $2 \mathrm{~mm}$ thick sample exposed to $20 \mathrm{~g}$ fire accelerant, $59 \%$ for the $4 \mathrm{~mm}$ thick, and $92 \%$ for the $6 \mathrm{~mm}$ thick samples (see also Table 2). For thicker samples, the influence of various protective measures is less significant compared to the $2 \mathrm{~mm}$ samples, because the high standard deviations for the determined residual strength prohibit a reliable ranking of the protective measures for these samples.

According to the observed residual ILSS, the recorded maximum temperatures at the center of the samples' backside are shown in Figure 17B. Uncoated CFRP samples exhibit the highest temperatures. As expected, temperatures increase with the amount of fire accelerant up to $366^{\circ} \mathrm{C}$ on $2 \mathrm{~mm}$ thick samples for $25 \mathrm{~g}$ thereof. All protective measures lead to a reduction of these temperatures, especially for increasing amounts of fire accelerant. For example, $20 \mathrm{~g}$ of fire accelerant leads to a temperature of $340{ }^{\circ} \mathrm{C}$ on pure CFRP, to $320^{\circ} \mathrm{C}$ in the presence of an additional copper mesh, to $315^{\circ} \mathrm{C}$ for a copper mesh and a top coat, to $300{ }^{\circ} \mathrm{C}$ for a top coat, and to $290{ }^{\circ} \mathrm{C}$ for an intumescent coating. Best protection by means of low temperatures is provided by an intumescent coating. For samples thicker than $2 \mathrm{~mm}$, the backside temperatures are in general lower. For the sole CFRP they are $307^{\circ} \mathrm{C}$ for $4 \mathrm{~mm}$ thick samples and $270{ }^{\circ} \mathrm{C}$ for the $6 \mathrm{~mm}$ samples, when applying $25 \mathrm{~g}$ fire accelerant (see above). Again, the application of a copper mesh and/or a coating reduces the backside temperatures, but the protective effect diminishes with increasing sample thickness and a comparable differentiation of the efficiency of the various protective measures is less significant. Only the application of an intumescent coating results in significantly lower backside temperatures. However, even for $6 \mathrm{~mm}$ thick samples all other protective measures lead to slightly lower temperatures compared to the pure CFRP.

Figure $17 \mathrm{C}$ provides the corresponding indication of matrix degradation at the samples' backside by means of infrared spectroscopy. For conditions, where low residual strength and high backside temperatures were observed, a pronounced matrix degradation is determined by a low intensity ratio of bands characteristic for epoxy resin and polyethersulfone. In contrast to ultrasonic testing, infrared spectroscopy allows a sensitive quantification of moderate thermal damage by characterizing matrix degradation at the panels surface. Even for samples with $5 \mathrm{~g}$ of applied fire accelerant, for which a thermal damage is typically not detected by ultrasonic testing (see Figures 9 and 13), infrared spectroscopy is able to measure a matrix degradation accompanied by a reduction of the band intensity ratio $\mathrm{I}_{1510 \mathrm{~cm}^{-1}} / \mathrm{I}_{1486 \mathrm{~cm}^{-1}}$ down to $71 \%$ for a $2 \mathrm{~mm}$ thick $8552 / \mathrm{IM} 7$ sample. 

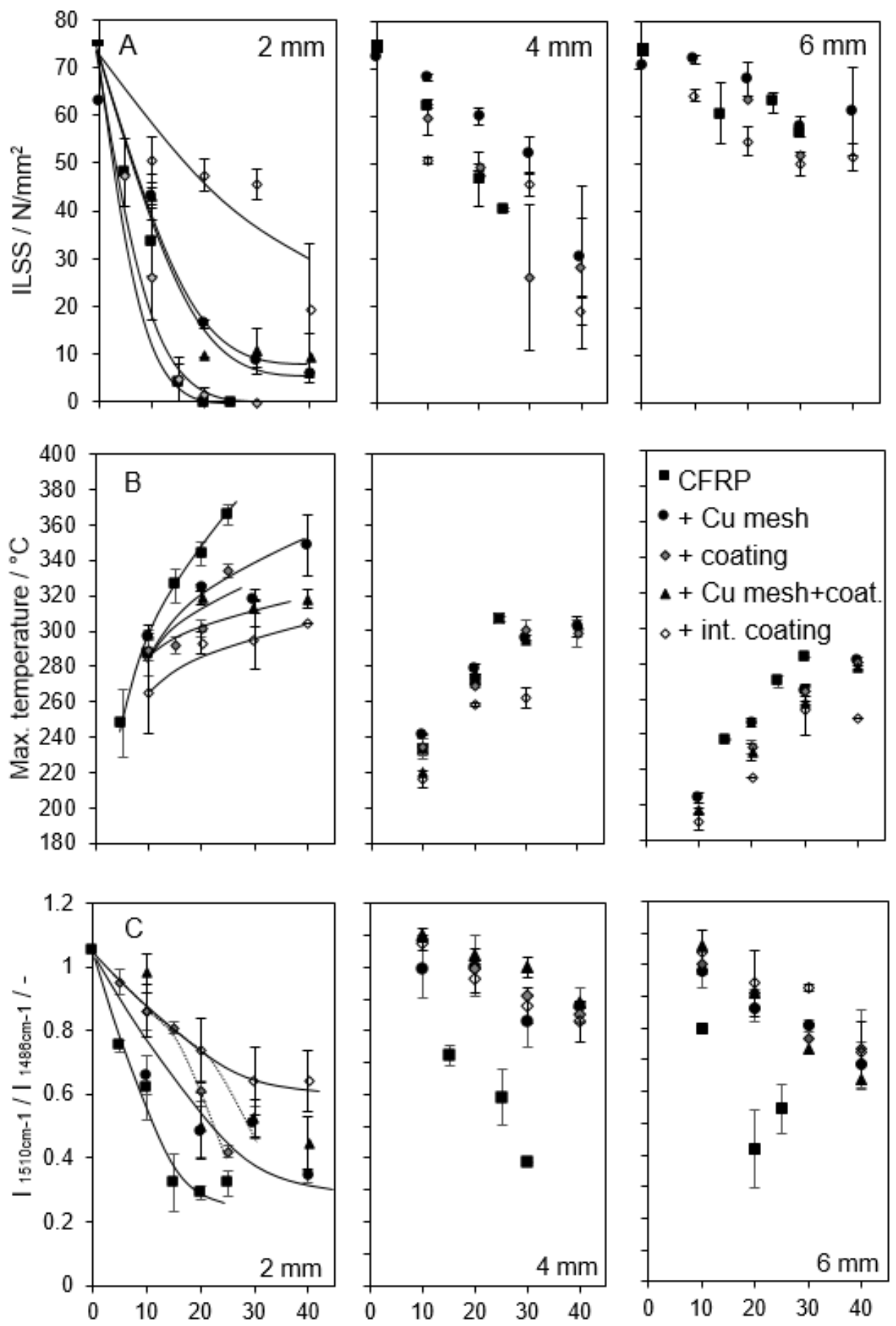

mass (fire accelerant) / g

Figure 17. Results for 2, 4, and $6 \mathrm{~mm}$ thick 8552/IM7 samples with various protective measures after impact of various amounts of fire accelerants: (A) Minimum interlaminar shear strength (ILSS); (B) maximum temperatures at the center of the backside; (C) Minimum intensity ratios of bands characteristic for EP $\left(1510 \mathrm{~cm}^{-1}\right)$ and PES $\left(1486 \mathrm{~cm}^{-1}\right)$.

Similar observations for residual strength, as well as backside temperatures and matrix degradation as explanation thereof are made for the CFRP M18-1/G939 (see Table 2).

\subsection{Empirical Correlation of Temperature, Matrix Degradation, and Residual Strength}

Received data for destructive and non-destructive testing are correlated in order to provide tools for a prediction of residual strength by non-destructive methods such 
as ultrasonic testing and infrared spectroscopy, for example, in case of failure analysis, as well as in order to provide a deep insight in the thermal degradation mechanism of CFRP during impact of improvised incendiary devises. Figure 18 shows correlations of matrix degradation traced by infrared spectroscopy (Figure 18A) and residual ILS strength (Figure 18B) with the maximum occurring backside temperatures for 8552/IM7. For increasing temperatures, matrix degradation increases, as expected and indicated by a lower intensity ratio of bands characteristic for epoxy resin and polyethersulfone $\left(\mathrm{I}_{1510 \mathrm{~cm}^{-1}} / \mathrm{I}_{1486 \mathrm{~cm}^{-1}}\right)$. Total of $2 \mathrm{~mm}$ thick samples (black filled data points) indicate the highest occurring temperatures at the right side of the diagram. The $6 \mathrm{~mm}$ thick samples (open data points) show the lowest matrix degradation and corresponding temperatures at the left and top part of the diagram. CFRP without the application of protective measures (large squares in Figure 18A) slightly deviate from the correlation of the rest of the data. For a certain temperature, pure CFRP show a more pronounced thermal damage, as damage is lower with the application of a coating. A linear correlation can be used to estimate occurring temperatures for various thick materials, when infrared spectroscopic data are available. However, prediction is not supposed to be precise, as the correlation coefficient is low $\left(R^{2}=0.63\right)$. Correspondingly, residual strength diminishes with increasing backside temperatures (Figure 18B). Again, $2 \mathrm{~mm}$ thick panels reach higher temperatures and lower residual strength compared to the thicker panels. The linear correlation is slightly better $\left(R^{2}=0.69\right)$ compared to the infrared spectroscopic data.

For failure analysis and repair, it is most important to predict the residual strength with a rapid non-destructive technique. Figure 18C presents residual ILSS dependent on the ratio of damaged to undamaged area in an ultrasonic C-scan. Hereby, larger damaged areas in principal correspond to lower minimum residual ILSS at the center of the samples, even if delamination depth is not considered, but is decisive for the damage [38]. The ratio is characteristic for the damage of the $100 \mathrm{~mm} \times 100 \mathrm{~mm}$ samples fixed in the sample holder, but it is not representative and applicable to assess a damage such as of an aircraft component. However, ultrasonic testing is proven to be able to quantify severe damage by improvised incendiary devices, even if the spread of data is high and prediction of residual strength is limited. As samples with applied intumescent coatings do not show a damage in the ultrasonic C-scan, data are not contained in Figure 18C. Infrared spectroscopy is more sensitive, and it is able to precisely detect the thermal damage. Figure 18D presents the correlation of matrix degradation characterized by IRspectroscopy and ILSS. For the pure CFRP, significant differences are observed for various thick panels. The $2 \mathrm{~mm}$ thick samples show the most pronounced drop in the band intensity ratio $\mathrm{I}_{1510 \mathrm{~cm}^{-1}} / \mathrm{I}_{1486 \mathrm{~cm}^{-1}}$, and therefore the most pronounced matrix degradation, when residual strength diminishes (16D1). This drop is increasingly flatter for 4 and $6 \mathrm{~mm}$ thick panels, as expected due to the lower backside temperatures of thick samples (see above). However, the formation of delaminations and the corresponding depth is decisive for residual ILSS [38]. As 4 and $6 \mathrm{~mm}$ thick samples retain areas without delaminations (see Figure 9), the drop of residual ILSS is less steep than for $2 \mathrm{~mm}$ thick samples, which are typically completely delaminated. A differentiation of panel thickness is not as clear for the samples additionally containing a copper mesh and or a top coat. Here, a continuous drop in the intensity ratio is observed for all sample thicknesses (Figure 18(D2)). Of course, thin panels show the lowest residual strength and most pronounced matrix degradation (lowest

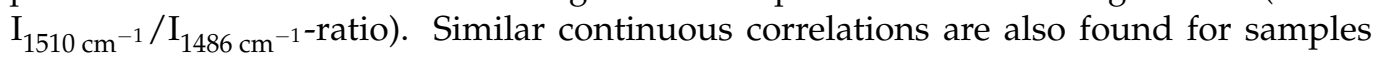
with a top coat and a copper mesh as well as for samples with a top coat only (data not depicted). Samples with an intumescent coating, in general retain high residual strength and therefore its drop are less pronounced with increasing matrix degradation. Only, when matrix degradation exceeds a certain limit value $\left(\mathrm{I}_{1510 \mathrm{~cm}^{-1}} / \mathrm{I}_{1486 \mathrm{~cm}^{-1}}\right.$ falls below 0.7), a breakdown in residual strength may occur (Figure 18(D3)). This limit value accompanied by the beginning formation of delaminations was already observed for corresponding irradiation experiments [38]. 

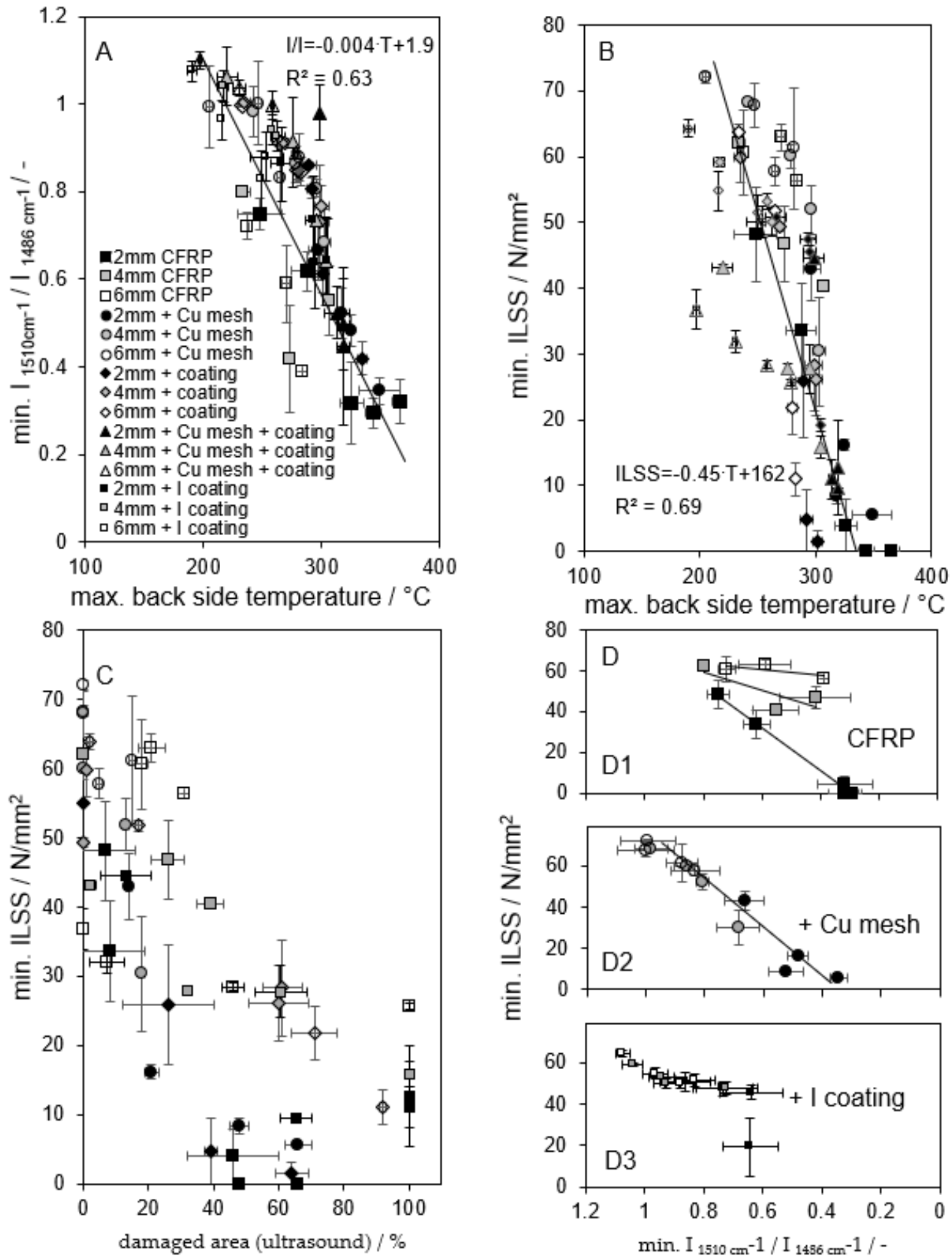

Figure 18. Correlation of data for 8552/IM7 panels after impact of fire accelerant:(A) matrix degradation characterized by

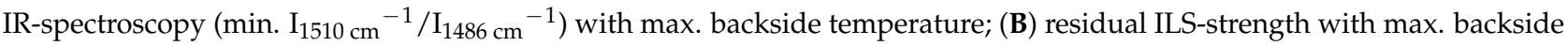
temperature; (C) ratio of damaged area in ultrasonic C-scan and minimum ILSS; (D) minimum ILSS and matrix degradation characterized by IR-spectroscopy.

In summary, temperature, matrix degradation, and residual strength after the impact of incendiary devices can be empirically correlated and non-destructive methods such as infrared spectroscopy and ultrasonic testing open a way to estimate the residual strength. 


\section{Conclusions}

This work focuses on short-term thermal degradation of composite materials induced by one-sided impact of improvised incendiary devices (IIDs). The aim is to correlate the heat damage of the polymer matrix induced by the IID to the residual strength for various material thicknesses and panel alignments as well as to characterize the degradation mechanism. Various protective measures are assessed. As large-scale fire tests with IIDs do not provide reproducible results, for a systematic study, dominant laboratory tests are performed with better controllable test conditions. Test results proof, that reached temperatures and test durations are comparable to the large-scale tests.

In general, CFRP are prone to severe damage by IIDs:

Especially thin panels and vertically aligned panels rapidly degrade and loose mechanical strength.

Sandwich structures containing thin CFRP parts lose mechanical integrity at comparably low heat impact by IIDs.

Higher amounts of fire accelerant lead to longer durations of heat impact and therefore increase thermal damage.

High temperature gradients and thermal strain occur inside the CFRP materials.

Cross sections for thicker panels exhibit limited areas with delaminations close to the surface, whereas thinner samples are damaged throughout the panel thickness.

Increasing panel thickness results in a delayed thermal degradation due to increasing heat capacity.

Decreasing strengths can be explained based on formed delaminations and matrix degradation.

For vertically orientated panels, resin matrix combusts, because the access of air is not hindered and the carbon fibers may act as wick. For horizontally aligned panels, the combustion of the fire accelerant does not lead to a significant contribution to the heat release by the matrix. Under these laboratory test conditions, the access of air is limited, and a preferably pyrolytic degradation of the matrix is accompanied by comparably low mass losses $(<5 \%)$.

Therefore, a simulation of heat impact on CFRP by IIDs is not precise for example when typical irradiation experiments in a cone calorimeter are conducted. The introduction of energy into the CFRP material and the access of air significantly differ. Even if the conducted laboratory scale tests better characterize the impact of IID on CFRP, they also can not represent the conditions of an arson attack in complete. But important information is gained, how certain conditions such as horizontal and vertical orientation of a CFRP component influence its thermal damage. A cone calorimeter in combination with the new sample holder is a valuable tool for this purpose, because it is not used in a typical way to determine reaction-to-fire properties by irradiation and forced combustion, as it is proven, that irradiation may not represent conditions of a heat impact by IID.

All investigated protective layers such as typical coatings, an integrated copper mesh, and an intumescent coating improve the performance of CFRP during an IID assault for $2 \mathrm{~mm}$ thick samples. However, the best protection is achieved by the intumescent coating. Even though, there is potential for improving the performance of an intumescent coating, as formed carbon residues may be combusted within the burning liquid fire accelerant.

Non-destructive testing methods, such as ultrasonic testing and infrared spectroscopy, have been proven to be valuable tools for identifying thermal damage of CFRP by IIDs. A prediction of occurring temperatures during an IID assault or residual strength afterwards is possible with a correlation to these data. For moderate thermal damage, only infrared spectroscopy is sensitive enough.

The presented results are obtained for high performance CFRP commonly used in defense industry. These epoxy-based materials do not easily ignite or are flame retarded. Both investigated CFRP materials behave similarly even if their composition differs, because of deviating thermoplastic tougheners or contained flame retardants. Composites with a polymer matrix, which easily ignites and continuously burns, are expected to behave 
significantly differently and damage induced by IIDs is expected to be even severe. Conditions of the laboratory tests with limited oxygen access to horizontally aligned panels, may better fit to the behavior of the investigated high performance CFRP during a real IID assault.

Funding: This research received no external funding.

Conflicts of Interest: The authors declare no conflict of interest.

\section{References}

1. Kolaitis, D.I. An experimental investigation of improvised incendiary devices used in urban riots: The "Molotov cocktail". In Proceedings of the 2nd IAFSS European Symposium of Fire Safety Science, Nicosia, Cyprus, 16-18 June 2015.

2. Tsaroom, S. Molotov cocktails and similar devices used by terrorists in Israel. J. Energetic Mater. 1986, 4, 325-338. [CrossRef]

3. Benmeir, P.; Lusthaus, S.; Talisman, R.; Ad-El, D.; Sagi, A.; Weinberg, A.; Eldad, A.; Neuman, A.; Wexler, M.R. Terrorist bombing with a 'Molotov cocktail' inside travelling cars: An old weapon for a new burn syndrome? Burns 1994, 20, 248-250. [CrossRef]

4. Fawaz, K.S. Fires and Related Incidents in Jordan (1996-2004). Fire Safety J. 2006, 41, 370-376.

5. Mehrkam, P.A.; Armstrong-Carroli, E.; Cochran, R. Characterization of Heat Damage in Grahite Epoxy Composites; Report; Naval Air Warfare Center: Warminster, PA, USA, 1994.

6. Schartel, B.; Hull, T.R. Development of fire-retarded materials-Interpretation of cone calorimeter data. Fire Mater. 2007, 31, 327-354. [CrossRef]

7. Pering, G.A.; Farrell, P.V.; Springer, G.S. Degradation of tensile and shear properties of composite exposed to fire or high temperature. In Springer Environmental Effects on Composite Materials; Technomic Publishing Company Inc.: Berlin, Germany, 1981.

8. Milke, J.A.; Vizzini, A.J. Thermal response of fibre-exposed composites. J. Compos. Technol. Res. 1991, 13, 145-151.

9. Pritt, H.L. Thermal Degradation of Graphite-Epoxy Composites; Final Report No. N62669-79-C-0270; Naval Air Development Center: Warminster, PA, USA, 1980.

10. Burcham, L.J; Eduljee, R.F.; Gillespie, J.W. Investigation on the microcracking behavior of bismaleimide composites: During thermal aging. Polym. Compos. 1995, 16, 507-517. [CrossRef]

11. Mascia, L.; Zhang, J. Mechanical properties and thermal aging of a perfluoroether-modified epoxy resin in castings and glass fibre composites. Composites 1995, 26, 379-385. [CrossRef]

12. Mallick, P.K. Non-Destructive Tests, Composites Engineering Handbook; CRC Press: New York, NY, USA, 1997.

13. Dara, I.H.; Ankara, A.; Akovali, G.; Suzer, S. Heat Damage Assessment of Carbon-fiber-Reinforced Polymer Composites by Diffuse Reflectance Infrared Spectroscopy. J. Appl. Polym. Sci. 2005, 96, 1222-1230. [CrossRef]

14. Shelley, P.; Vahey, P.; Werner, G.; Seelenbinder, J. Handheld Infrared Spectroscopy for Composite Non-Destructive Testing. In Proceedings of the SAMPE 2011, Long Beach, CA, USA, 23-26 May 2011.

15. Shelley, P.; Vahey, P.; Werner, G. Thermal Effect Measurement with Mid-Infrared Spectroscopy. Patent EP2138829A1, 30 December 2009.

16. Wolfrum, J.; Eibl, S.; Lietch, L. Rapid Evaluation of long-term thermal degradation of carbon fibre epoxy composites. Compos. Sci. Technol. 2009, 69, 523-530. [CrossRef]

17. Wolfrum, J.; Whitney, E.; Eibl, S. Approaches to understand and predict the influence of rapid heat-up on degradation and strength of carbon fibre polymer matrix composites. J. Compos. Mater. 2017, 51, 2435-2447. [CrossRef]

18. Eibl, S.; Wolfrum, J. Prospects to separately estimate temperature and duration of a thermal pre-load on a polymer matrix composite. J. Comp. Mat. 2013, 47, 3011-3025. [CrossRef]

19. Dohmen, B.; Schmidt, H.; Tröster, B. Quantifizierung der Thermischen Schädigung von CFK beim Brandanschlag (Quantification of Thermal Damage of CFRP Due to Arson Attack) Project Report 2015; Wehrwissenschaftliches Institut für Werk und Betriebsstoffe: Erding, Germany, 2015.

20. Eibl, S. Influence of carbon fibre orientation on reaction-to-fire properties of polymer matrix composites. Fire Mater. 2012, 36, 309-324. [CrossRef]

21. Eibl, S. Influence of unwoven roving and woven fabric carbon fiber reinforcements on reaction-to-fire properties of polymer matrix composites. Fire Mater. 2020, 44, 557-572. [CrossRef]

22. Product Data Sheets, Hexcel Inc. Available online: www.hexcel.com (accessed on 2 March 2021).

23. Eibl, S. Observing inhomogeneity of plastic components in carbon fibre reinforced polymer materials by ATR-FTIR-spectroscopy in the micrometer scale. J. Compos. Mater. 2008, 42, 1231-1246. [CrossRef]

24. Technical Data Sheet, Fa; Mankiewicz Gebr. \& Co: Hamburg, Germany; Available online: www.Mankiewicz.com (accessed on 2 March 2021).

25. DIN EN ISO 2813: Paints and Varnishes-Determination of Specular Gloss of non-Metallic Paint Films at 20 Degrees, 60 Degrees and 85 Degrees; Beuth: Berlin, Germany, 1999.

26. The Federal Office of Bundeswehr Equipment, Information Technology and In-Service Support (BAAINBw). Technical Specification: 8010-0312 (10.2015) Deckbeschichtungsstoffe für Bundeswehrgeräte 2-Komponenten-Polyurethan Deckbeschichtungsstoffe (lösemittelhaltig und Wasserverdünnbar); The Federal Office of Bundeswehr Equipment: Koblenz, Germany, 2015. 
27. Eibl, S. Reaction-to-fire properties of polymer matrix composites with integrated intumescent barriers. Fire Mater. 2015, 39, 658-674. [CrossRef]

28. ISO 5660:2002. Reaction-to-Fire Tests-Heat release, Smoke Production and Mass Loss Rate; Beuth Verlag: Berlin, Germany, 2002.

29. DIN EN 2563:1997. Aerospace Series- Carbon Fibre Reinforced Plastics-Unidirectional Laminates; Determination of Apparent Interlaminar Shear Strength; Beuth Verlag: Berlin, Germany, 1997.

30. DIN EN 53293. Prüfung von Kernverbunden, Biegeversuch; Beuth Verlag: Berlin, Germany, 1982.

31. Speight, J.G. Handbook of Industrial Hydrocarbon Processes; Gulf Professional Publishing, Elsevier: Amsterdam, The Netherlands, 2020; ISBN 978-0-12-809923-0.

32. Seggewiß, P. Experimentelle und numerische Untersuchung des Verhaltens kohlenstofffaserverstärkter Epoxidmatrix-Systeme unter einseitiger thermischer und gleichzeitig mechanischer Belastung, (Experimental and Numeric Investigation of Epoxy based CFRP under Simultanious Thermal and Mechanical Load). Ph.D. Thesis, University of the German armed Forces, Munich, Germany, 2011.

33. Bondzic, S.; Hodkin, J.; Krstina, J.; Mardel, J. Chemistry of thermal aging in aerospace epoxy composites. J. Appl. Polym. Sci. 2005 100, 2210-2219. [CrossRef]

34. Eibl, S. Comparison of a surface and a bulk analytical technique for the distinct quantification of a moderate thermal pre-load on a polymer matrix composite. Polym. Degrad. Stab. 2017, 135, 31-42. [CrossRef]

35. Dao, B.; Hodkin, J.; Krstina, J.; Mardel, J.; Tian, W. Accelerated aging versus realistic aging in aerospace composite materials, II chemistry of thermal aging in a structural composite. J. Appl. Polym. Sci. 2006, 102, 3221-3232. [CrossRef]

36. Musto, P.; Ragosta, G.; Russo, P.; Mascia, L. Thermal-oxidative degradation of epoxy-bismaleimide networks: Kinetics and mechanisms. Macromol. Chem. Phys. 2001, 202, 3445-3458. [CrossRef]

37. Eibl, S.; Swanson, D. Influence of out-of-plane fiber orientation on reaction-to-fire properties of carbon fiber reinforced polymer matrix composites. Fire Mater. 2018, 42, 234-243. [CrossRef]

38. Vetter, M.; Bibinger, J.; Zimmer, F.; Eibl, S.; Gudladt, H.J. Characterization of one-sided thermal damage of carbon fiber reinforced polymers by means of depth profiles. J. Comp. Mat. 2020, 54, 3699-3713. [CrossRef] 